San Jose State University

SJSU ScholarWorks

Master's Theses

Master's Theses and Graduate Research

1994

\title{
The requirement of niacin and its biosynthesis from tryptophan in the nematode, Caenorhabditis elegans
}

\section{Zhiping Li}

San Jose State University

Follow this and additional works at: https://scholarworks.sjsu.edu/etd_theses

\section{Recommended Citation}

$\mathrm{Li}$, Zhiping, "The requirement of niacin and its biosynthesis from tryptophan in the nematode, Caenorhabditis elegans" (1994). Master's Theses. 774.

DOI: https://doi.org/10.31979/etd.a76f-6t2y

https://scholarworks.sjsu.edu/etd_theses/774

This Thesis is brought to you for free and open access by the Master's Theses and Graduate Research at SJSU ScholarWorks. It has been accepted for inclusion in Master's Theses by an authorized administrator of SJSU ScholarWorks. For more information, please contact scholarworks@sjsu.edu. 


\section{INFORMATION TO USERS}

This manuscript has been reproduced from the microfilm master. UMI films the text directly from the original or copy submitted. Thus, some thesis and dissertation copies are in typewriter face, while others may be from any type of computer printer.

The quality of this reproduction is dependent upon the quality of the copy submitted. Broken or indistinct print, colored or poor quality illustrations and photographs, print bleedthrough, substandard margins, and improper alignment can adversely affect reproduction.

In the unlikely event that the author did not send UMI a complete manuscript and there are missing pages, these will be noted. Also, if unauthorized copyright material had to be removed, a note will indicate the deletion.

Oversize materials (e.g., maps, drawings, charts) are reproduced by sectioning the original, beginning at the upper left-hand corner and continuing from left to right in equal sections with small overlaps. Each original is also photographed in one exposure and is included in reduced form at the back of the book.

Photographs included in the original manuscript have been reproduced xerographically in this copy. Higher quality $6^{\prime \prime} \times 9^{\prime \prime}$ black and white photographic prints are available for any photographs or illustrations appearing in this copy for an additional charge. Contact UMI directly to order.

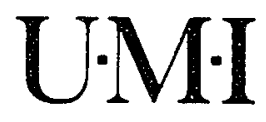

University Microfilms International

A Bell \& Howell Information Company 

Order Number 1358198

The requirement of niacin and its biosynthesis from tryptophan in the nematode, Caenorhabditis elegans*

Li, Chih-Ping, M.S.

San Jose State University, 1994

$\mathrm{U} \cdot \mathrm{M} \cdot \mathrm{I}$

300 N. Zeeb Rd.

Ann Arbor, MI 48106 

THE REQUIREMENT OF NIACIN AND ITS BIOSYNTHESIS FROM

TRYPTOPHAN IN THE NEMATODE, Caenorhabditis elegans

\begin{abstract}
A Thesis
Presented to

The Faculty of the Department of Nutrition and Food science San Jose State University
\end{abstract}

\author{
In Partial Fulfillment \\ of the Requirements for the Degree \\ Master of Science \\ in Nutritional Science
}

By

Chih-Ping Li

May, 1994 
(C) 1994

Chih-Ping Li

ALL RIGHTS RESERVED 
APPROVED FOR THE DEPARTMENT

OF NUTRITION AND FOOD SCIENCE

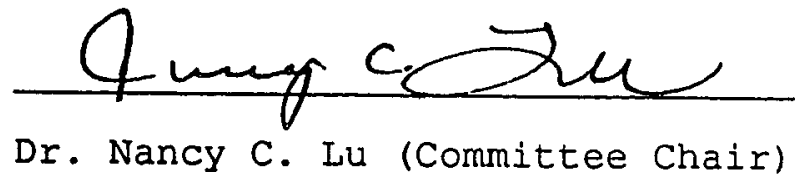

hung h. Me Proud

Dr. Lucy M. McProud

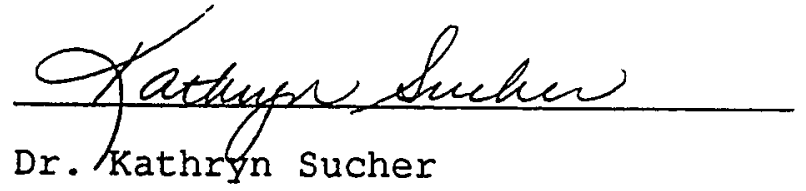

APPROVED FOR THE UNIVERSITY

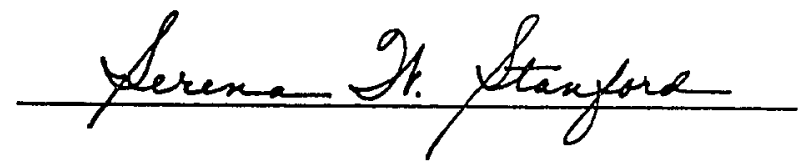




\section{ABSTRACT}

THE REQUIREMENT OF NIACIN AND ITS BIOSYNTHESIS FROM

TRYPTOPHAN IN THE NEMATODE, Caenorhabditis elegans

by Chih-Ping $\mathrm{Li}$

The requirement for niacin was determined in the freeliving nematode, caenorhabditis elegans (c. elegans). The growth-promoting activity of 0 (control), $0.060,0.30,1.5$, $7.5,38,190$, and $940 \mu \mathrm{g} / \mathrm{ml}$ of nicotinic acid (N), nicotinamide $(\mathrm{Nm})$, and nicotinic acid plus nicotinamide $(\mathrm{N}+$ Nm) was quantitatively determined. The deficient, optimal, and toxic levels for $\mathrm{N}$ or $\mathrm{Nm}$ were below 1.5 , between 1.5 to 190, and above $190 \mu \mathrm{g} / \mathrm{ml}$, respectively. Nicotinic acid (N) demonstrated greater growth-promoting activity than Nm at all levels. The deficient, optimal, and toxic levels for $\mathrm{N}$ $+\mathrm{Nm}$ were below 0.30 , between 0.30 to 38 , and above 38 $\mu \mathrm{g} / \mathrm{ml}$, respectively. In studying the role of tryptophan as a niacin precursor, the basal medium (containing $0.30 \mu \mathrm{g} / \mathrm{ml}$ of $\mathrm{N}$ and $180 \mu \mathrm{g} / \mathrm{ml}$ of tryptophan) was supplemented with additional $\mathrm{N}(0,0.60$, or $1.2 \mu \mathrm{g} / \mathrm{ml})$ or additional tryptophan $(0,180,370,550,740$, or $920 \mu \mathrm{g} / \mathrm{ml})$. Using Finney's slope ratio procedure, the conversion ratio of tryptophan to niacin was determined to be 500:1 in $\mathrm{c}$. elegans. 


\section{ACKNOWLEDGEMENTS}

I am extremely grateful to Dr. Nancy Lu, Committee Advisor, for her advice, guidance and support on my Master's thesis. I wish to thank my committee members, Dr. Lucy MCProud and Dr. Kathryn Sucher, for their support and editing of the manuscript. I would also like to thank the San Jose State University Foundation for funding this research.

My sincere appreciation goes to my husband, Iung-Shan, for his patience, encouragement, and understanding during the achievement of this personal goal. 


\section{PREFACE}

The following is a publication style thesis. Chapter 2 is a journal article written according to guidelines published by the Journal of Nutrition. Chapters 1 and 3 are written according to guidelines outlined in the publication Manual of the American Psychological Association (3rd. edition), 1990 . 
Iist of Figures . . . . . . . . . . . . . . . . ix List of Tables. . . . . . . . . . . . . . . . . . x CHAPTER

1. INTRODUCTION AND REVIEW OF IITERATURE. . . . . . . 1 Introduction . . . . . . . . . . . . . 1 Review of Literature . . . . . . . . . . . 2 The Nematode, $\subseteq$. elegans . . . . . . . . 2 Biological Characteristics . . . . . . 2 Nutritional Requirements.. . . . . . . . 5 Vitamins . . . . . . . . . . . . 5 Minerals . . . . . . . . . . . 6 Amino Acids. . . . . . . . . . . . 6 Other Growth Factors . . . . . . . . 7 Energy Source. . . . . . . . . . . 7 Culture Conditions . . . . . . . . 8 Niacin . . . . . . . . . . . . . 10

The Function of Niacin . . . . . . . . 10 Absorption and Metabolism of Niacin. . . . . 14 Tryptophan-Niacin Conversion . . . . . . 16 Nutritional Requirements of Niacin in Different Species. . . . . . . . . 18 Toxicity... . . . . . . . . . . 20

2. JOURNAL ARTICLE. . . . . . . . . . . . . 23 


\begin{abstract}
. . . . . . . . . . . . . . 26
Introduction . . . . . . . . . . . . . . 27

Materials and Methods. . . . . . . . . . 28

Stock Media and Culture. . . . . . . . . 28

Niacin Requirement . . . . . . . . . . 29

Tryptophan Requirement . . . . . . . . . 30
\end{abstract}

Determination of Tryptophan-Niacin Conversion

Ratio. . . . . . . . . . . . . 30

Statistical Analysis . . . . . . . . . 31

Results. . . . . . . . . . . . . . 31

Quantitative Requirement of Niacin . . . . . 31

Growth-Promoting Activities of Nicotinic

Acid And/Or Nicotinamide . . . . . . . . 33

Quantitative Requirement of Tryptophan . . . . 33

Conversion of Tryptophan to Niacin . . . . . 34

Discussion . . . . . . . . . . . . . 34

References . . . . . . . . . . . . . . 44

3. SUMMARY AND RECOMMENDATIONS. . . . . . . . . 49

Summary. . . . . . . . . . . . . . . 49

Recommendations. . . . . . . . . . . 50

REFERENCES. • . . . . . . . . . . . . . . 51

APPENDIX I. . . . . . . . . . . . . . . . 60 


\section{List of Figures}

Eigures

Page

A Anatomy of c. elegans. . . . . . . . . . . . . 4

B Structures of the Vitamins Nicotinic Acid and Nicotinamide and the Coenzymes NAD and NADP • . • • . . . . . . . . . . . . . . 11

C The Mechanism of the Coenzymatic Function of Niacin. . 13

D The Metabolism of Tryptophan and Nicotinamide Nucleotides. . . . . . . . . . . . . . 15

1 Effect of Different Levels of Nicotinic Acid (N), Nicotinamide $(\mathrm{Nm})$, and Nicotinic Acid Plus Nicotinamide $(\mathrm{N}+\mathrm{Nm})$ on Population Growth in c. elegans . . . . . . . . . . . . . . 40

2 Effect of Different Levels of Tryptophan on

Population Growth in c. elegans. . . . . . . . . 41

3 Regression of the Population Growth for $c$. elegans

at 16 Days of Cultivation ( $Y$ ) on Nicotinic Acid

Supplement $\left(\mathrm{X}_{1}\right)$ or Tryptophan Supplement $\left(\mathrm{X}_{2}\right)$. . . 42

4 The Metabolism of Tryptophan and Nicotinamide Nucleotides. . . . . . . . . . . . . . 43 


\section{List of Tables}

Tables

Rage

I Niacin Requirements of Different Species . . . . . 19 
CHAPTER 1

INTRODUCTION AND REVIEW OF LITERATURE

Introduction

Caenorhabditis elegans (c. elegans) is a free living nematode that can be cultivated under axenic (germ-free) conditions. This nematode has a short life-cycle (34 days) (Croll \& Mathews, 1977), a rapid generation time (3.5 days) and the ability to be cultivated in large quantities for bioassay under defined and controlled conditions (Marx, 1984). Therefore, it has become widely used as a model for genetic (Kenyon, 1988), biological (Zuckerman, 1981), and nutritional (Lu et al., 1983; Bolla, 1987; Lu \& Goetsch, 1993) research. In 1962, Nicholas et al. reported that $c$. elegans failed to reproduce if niacin was omitted from the medium. However, the quantitative requirement of niacin necessary for optimal growth was not determined.

Niacin is a collective term that includes nicotinic acid and nicotinamide, both natural forms of the vitamin with niacin activity (Nomenclature Policy, 1979). Tryptophan, a precursor for niacin in animals, also contributes to niacin nutriture. This was first demonstrated in experiments with rats that were fed diets high in corn and low in niacin by Krehl and his coworkers 
(1945). They found that either niacin or tryptophan overcame the dietary deficiency. In humans, it is estimated that $60 \mathrm{mg}$ tryptophan can be converted to $1 \mathrm{mg}$ niacin (Goldsmith et al., 1961).

The objectives of this study were: 1) to quantitatively determine the niacin requirement for optimal population growth of the nematode, $\underline{c}$. elegans; 2) to compare the growth-promoting activities of the two forms of niacin, nicotinic acid and nicotinamide; and 3) to determine the efficiency of tryptophan as a niacin precursor in $\underline{c}$. elegans.

Review of Iiterature

The Nematode, $\underline{c}$ elegans

Biological Characteristics

Caenorhabditis elegans (c. elegans) is a free-living microscopic nematode, which has been cultivated under germfree conditions (Riddle, 1982). Since it is a species consisting almost entirely of hermaphroditic, selffertilizing individuals (Brun, 1965); a large population (approximately 90,000 nematodes per $\mathrm{ml}$ of medium) can be cloned from a single hermaphrodite for bioassay. Therefore, c. elegans has become widely used as an animal model for genetic (Kenyon, 1988), biological (Zuckerman, 1981), and nutritional (Lu et al., 1983; Bolla, 1987; Lu \& Goetsch, 
1993) research.

C. elegans is cylindrically shaped and tapered at both ends (Figure A). Adult nematodes of $c$. elegans are smal (about 1 millimeter in length and 0.1 millimeter in width), and consist of approximately 1000 somatic cells (Marx, 1984). This species has a short life cycle (34 days) (Croll \& Mathews, 1977); and the fertilized egg develops into a mature animal in only 3.5 days (Marx, 1984). Normally, the Iife cycle of $c$. elegans consists of six stages: the egg, four larval stages, and, the adult. The larva progresses through a series of four molts to adulthood (Kenyon, 1988). In the absence of food, however, the second molt produces a dauer larva which has an altered cuticle and can withstand adverse conditions. When presented with food, the dauer larva molts and continues the normal progress toward adulthood (Riddle, 1982).

The growth and reproduction of $c$. elegans are very sensitive to temperature. The optimal temperature is $18^{\circ}$ to $22^{\circ} \mathrm{C}$ (Croll \& Mathews, 1977). At $18^{\circ} \mathrm{C}, \boldsymbol{C}$. elegans shows an average fecundity of 141 offspring per hermaphrodite (Fatt and Dougherty, 1963). When the growth conditions are changed from $18^{\circ} \mathrm{C}$ to $23^{\circ} \mathrm{C}$, the resulting adult has a very low fecundity. If the succeeding generations are kept at $23^{\circ} \mathrm{C}$, fecundity decreases, and complete sterility is reached by the fifth or sixth generation (Brun, 1965). Thus there 

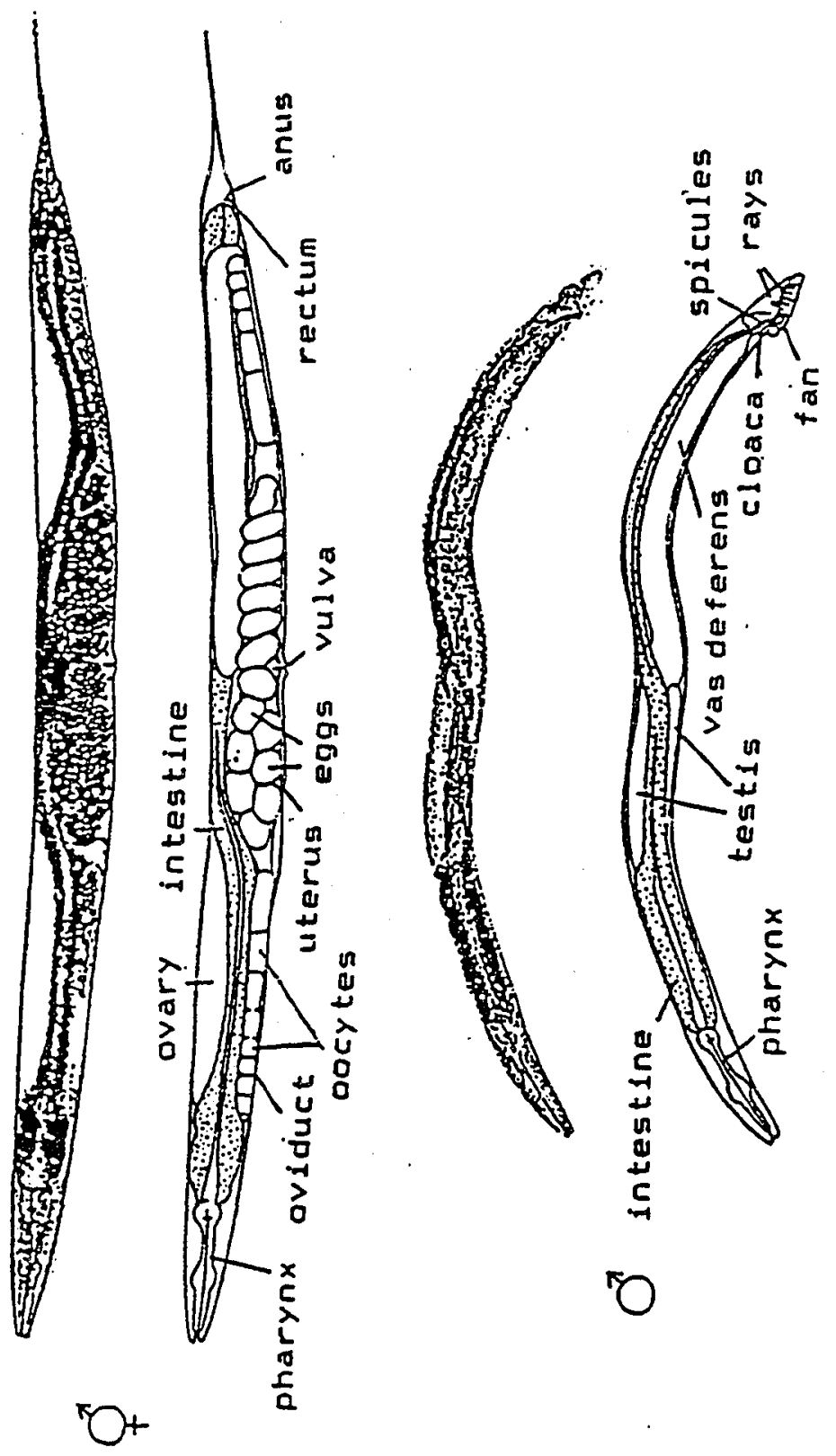

ลิ

$\bar{\partial}$

옴

우

\begin{tabular}{l}
0 \\
5 \\
1 \\
\hline \\
0 \\
0
\end{tabular}

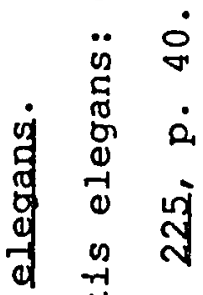

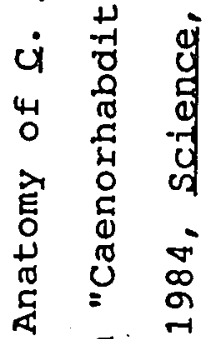

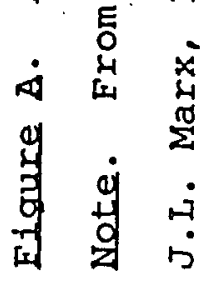


exists between normal (around $20^{\circ} \mathrm{C}$ ) and immediately sterilizing (above $24^{\circ} \mathrm{C}$ ) temperatures, a range that leads to the extinction of the strain within a few generations. The nutritional requirements of $c$. elegans and $c$. briggsae have been extensively studied. These two species of nematodes are closely related to each other. They differ only by genetic composition and the ability to interbreed (Friedman et al., 1977; Nicholas, 1984). Some papers published on $\mathcal{c}$. briggsae may in fact describe work on $\underline{C}$. elegans (Nicholas 1984). Nutritional requirements.

Vitamins. Nicholas et al. (1962) reported that thiamin, riboflavin, folic acid, niacin, pantothenic acid, and pyridoxine are required for the normal growth and reproduction of $\boldsymbol{c}$. briggsae. $c$. elegans exhibits similar vitamin requirements. $c$. elegans requires a minimal thiamin concentration of $0.075 \mu \mathrm{g} / \mathrm{ml}$ of culture media for optimal population growth (Augustin, 1992). Pyridoxamine, pyridoxine, and pyridoxal phosphate (vitamin $B_{6}$ ) promote growth in $c$. elegans (Sun et al., 1986). In vitamin $\mathrm{B}_{6}^{-}$ deficient nematodes, tryptophan metabolites (xanthurenic and kynurenic acids) accumulate in the culture medium during the tryptophan-load test. These studies indicate that $\mathcal{C}$. elegans requires vitamin $\mathrm{B}_{6}$.

The folic acid, vitamin $B_{12}$, and biotin requirements of 
c. elegans have also been assessed. In 1974, Lu et al. found that the accumulation of formimino-L-glutamic acid (FIGLU) in nematode tissues is related to folic acid deficiency. It was suggested that folic acid is required for the catabolism of histidine in nematodes. Lu et al. (1976) reported that the biosynthesis of methionine from homocysteine requires both vitamin $B_{12}$ and folic acid. $A$ biotin requirement was demonstrated by adding avidin, a protein that inhibits the uptake of biotin, to the culture medium (Nicholas \& Jantunen, 1963).

Minerals. The quantities of magnesium, sodium, potassium, manganese, calcium, and copper required by $\mathrm{c}$. elegans were determined by Lu and coworkers in 1983. An individual mineral deficiency was developed by deleting the mineral from the basal medium. The quantitative requirements for each mineral were determined to be 73,300 , $530,6.3,1500$, and $7.2 \mu \mathrm{g} / \mathrm{mI}$, respectively. Zinc is also an essential mineral for $\mathcal{c}$. elegans. Weber (1992) found that a level of 4.9 to $37 \mu \mathrm{g} / \mathrm{ml} \mathrm{zinc}$ in the media supported optimal growth in $\mathcal{c}$. elegans.

Amine acids. The amino acid requirements of $\mathrm{c}$. briggsae were investigated by Vanfleteren (1973). Arginine, histidine, isoleucine, leucine, lysine, methionine, phenylalanine, threonine, tryptophan, and valine are not synthesized by nematodes at levels high enough to permit 
reproduction; they are referred to as essential amino acids. On the other hand, alanine, asparagine, cysteine, glutamate, glutamine, glycine, proline, serine, and tyrosine, are synthesized by $c$. elegans; they are referred to as nonessential amino acids.

ether growth factors. In 1968, Hieb and Rothstein showed that $\mathbf{c}$. briggsae requires sterol. The sterol requirement of $c$. elegans can be satisfied by a single sterol or a mixture of sterol compounds. Media containing ergosterol, 7-derydrocholesterol, $\beta$-sitosterol, or stigmasterol support rapid reproduction. Population growth was comparable to that obtained with a mixture of sterols. In 1977, Lu et al. found the optimal level of $\beta$-sitosterol required by $c$. elegans to be $50 \mu \mathrm{g} / \mathrm{ml}$. c. briggsae requires heme (an iron-concaining porphyrin compound). Hiej et al. (1970) demonstrated that pure myoglobin, hemoglobin, cytochrome $c$, and hemin can substitute effectively for the liver fraction in the medium. Cytochrome $c$ is the most effective heme source for promoting growth and reproduction in c. briggsae, and its functions are similar to that of myoglobin in the higher animals.

Energy source. The energy requirement of $c$. elegans can be met by either potassium acetate or glucose. In 1978, Lu et al. reported that potassium acetate $(5 \mathrm{mg} / \mathrm{ml})$ in media containing a minimal amount of glucose $(1.3 \mathrm{mg} / \mathrm{ml})$ can 
be used as an energy source by nematodes. Fatty acids can also be used as an energy source because fatty acids can be metabolized to acetate by $\beta$-oxidation. The fatty acid oleate (or stearate) was more active for population growth in $c$. briggsae, while linoleate was less active on both a weight and molar basis. Furthermore, Lu et al. (1978) reported that other lipid-related compounds (Tween 80, Tween 85, ethanol, and n-propanol) can greatly stimulate population growth in $c$. briggsae in place of undefined proteinaceous sources, e.g. casamino acids. In fact, these Iipid-related compounds are even more potent than casamino acids in the basal medium.

Hansen and Buecher (1970) found that reproduction of $\underline{c}$. elegans was impaired by the omission of glucose and trehalose from basal medium. Lu and Goetsch (1993) reported that $\boldsymbol{c}$. elegans can utilize carbohydrates, especially glucose as a very effective energy sources. Their results indicate that a glucose concentration of $32.5 \mathrm{mg} / \mathrm{ml}$ should be used to replace the concentration of $1.3 \mathrm{mg} / \mathrm{ml}$ originally used in the defined medium for optimal growth of $\mathrm{c}$. elegans. With the increased level of glucose, potassium acetate is no longer needed in the medium.

culture conditions

In 1962, Tomlinson and Rothstein reported that cultivation of free-living nematodes under axenic (germ- 
free) conditions required a semi-defined medium. This medium was composed of two parts, a chemically defined portion and a small quantity of undefined materials. The most satisfactory chemically defined modium previously reported is Cpenerhabditis briggsae Maintenance Medium (CbMM) (Buecher et al., 1966). CbMM is an extremely rich medium composed of pre-determined amounts of amino acids, vitamins, nucleic acids, minerals, glutathione, glucose, and other growth factors. The undefined materials are obtajned from mammalian liver, chick embryo, and/or bacteria (Nicholas \& Jantunen, 1963). A variety of proteinaceous sources have also been used to provide unidentified growth factors, including commercially available products such as soy peptone (Lu et al., 1976), egg albumin (Buecher et al., 1966), and casamino acids (Lu et al., 1974). More recently, c. elegans has been cultivated axenically in a chemically defined medium consisting of CbMM and three additional defined compounds: $\beta$-sitosterol (sterol source) (Hieb \& Rothstein, 1968; Lu et al., 1977), cytochrome c (heme source) (Hieb et al., 1970), and potassium acetate (energy source) (Lu et al., 1978). In 1993, Iu and Goetsch demonstrated that glucose at $32.5 \mathrm{mg} / \mathrm{ml}$ (instead of 1.3 $\mathrm{mg} / \mathrm{ml}$ in the CbMM) can completely replace potassium acetate as the energy source in the nematode. Based on this study, the chemically defined medium used for cultivation of $c$. 
elegans has been modified to: CbMM containing $32.5 \mathrm{mg} / \mathrm{ml}$ glucose, $50 \mu \mathrm{g} / \mathrm{ml}$ cytochrome $\mathrm{c}$ and $50 \mu \mathrm{g} / \mathrm{ml} \beta$-sitosterol. The newly developed medium consists of 55 compounds and is named $C$. elegans Maintenance Medium (CeMM) (Appendix I) (Lu \& Goetsch, 1993).

\section{Niacin}

Niacin (Figure B) is a collective term for two forms of the vitamin with niacin activity: nicotinic acid and nicotinamide. The term "niacin" is used as a generic descriptor of pyridine 3-carboxylic acid and derivatives that exhibit qualitatively the biological activity of nicotinic acid and nicotinamide (Nomenclature Policy, 1979). The Function of Niacin

The coenzyme forms of niacin are nicotinamide adenine nucleotide (NAD) and nicotinamide adenine dinucleotide phosphate (NADP) (Figure B). Hundreds of enzymes require the nicotinamide moiety (NAD or NADP) as coenzymes. The most important function of the coenzymes is to help bring about the action of the enzymes known as dehydrogenases, which are essential in oxidation-reduction reactions and catalyze such diverse reactions as the conversion of alcohols (often sugars and polyols) to aldehydes or ketones, hemiacetals to lactones, aldehydes to acids, and certain amino acids to keto acids (Snell, 1953). The mechanism of 
Vitamins

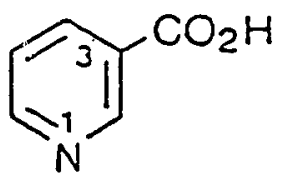

$\left(\begin{array}{c}3 \\ 1\end{array} \mathrm{CONH}^{2}\right.$

Nicotinic acid

Nicotinamide

\section{coenzymes}

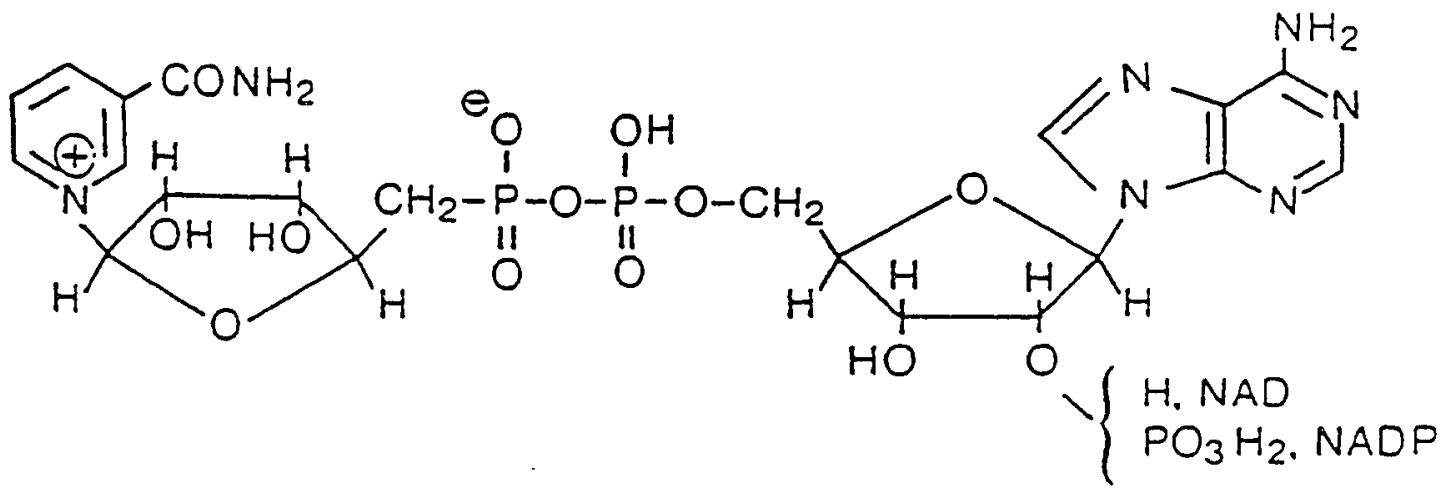

NAD and NADP

Eigure B. Structures of the vitamins nicotinic acid and nicotinamide and the coenzymes NAD and NADP. 
the coenzymatic function of niacin is shown in Figure $C$. In general, NAD-dependent enzymes are involved in catabolic reactions, whereas NADP-dependent systems are more common to biosynthetic reactions (McCormick, 1988).

Nicotinic acid is reported to be a component of glucose tolerance factor (GTF), which facilitates the binding of insulin to its receptor (Mertz et al., 1974). Urberg and Zemel (1987) conducted a study where 16 healthy elderly persons were given $200 \mu \mathrm{g}$ chromium $(\mathrm{Cr}), 100 \mathrm{mg}$ nicotinic acid or both daily for 28 days. Fasting serum glucose and glucose tolerance were not affected by $\mathrm{Cr}$ or nicotinic acid alone. The combined Cr-nicotinic acid supplement caused a 15\% decrease in a total integrated glucose area and a 7 웅 decrease in fasting serum glucose. The results suggest that the inability to respond to $\mathrm{Cr}$ supplementation may result from suboptimal levels of dietary nicotinic acid. Lee et al. (1961) reported that nicotinic acid (but not nicotinamide) had an "insulin-like" effect on rat epididymal fat pad tissue, as it increased the rate of glucose metabolism and lipogenesis. Similarly, Taylor and Halpern (1979) found that nicotinic acid increased the rate of conversion of $[1-14 \mathrm{C}]-g$ lucose to ${ }^{14} \mathrm{CO}_{2}$ and the rate of glucose disappearance from the incubation medium in isolated rat adipocytes. 


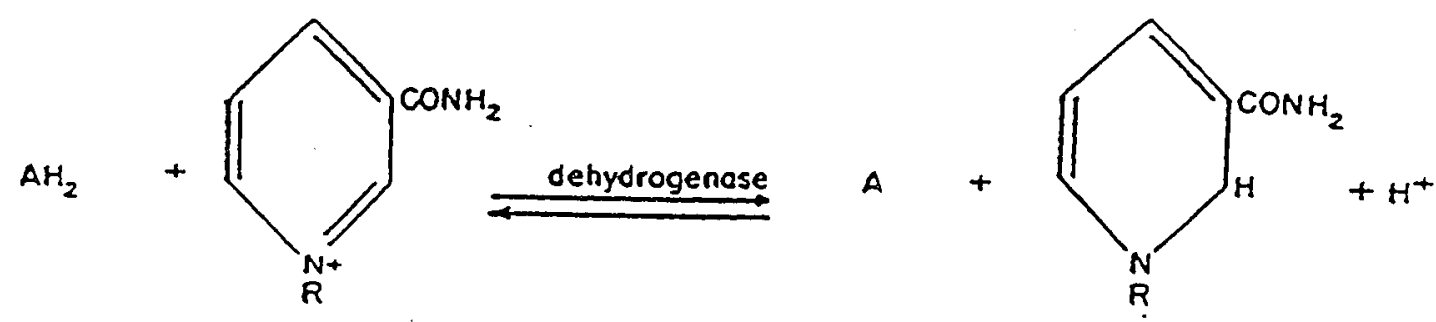

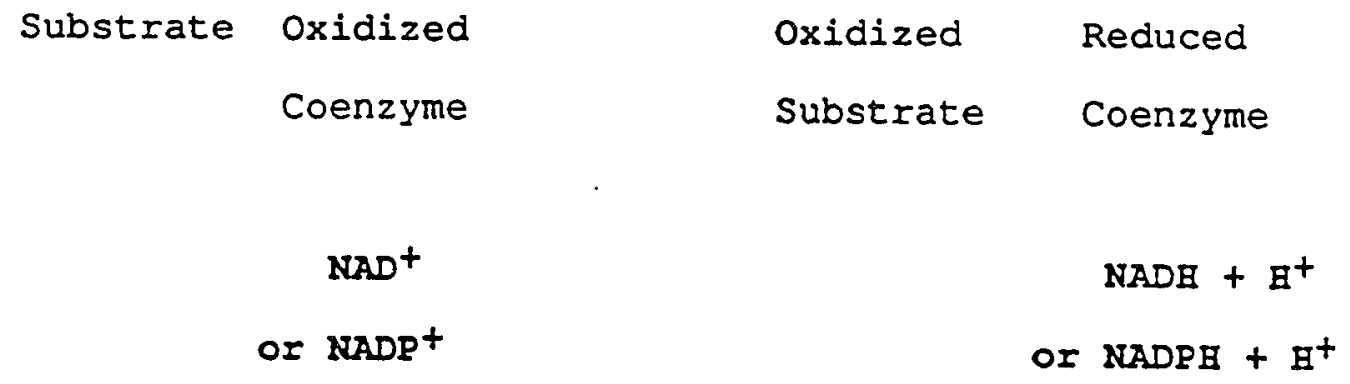

Eigure $c$. The mechanism of the coenzymatic function of niacin.

Note. From "Summary of known metabolic functions of nicotinic acid, riboflavin, and vitamin $B_{6}$ " by E.E. Snell, 1953, Rhysiological Reviews, 33, p. 510. 
Absorption and Metabolism of Niacin

In humans, dietary niacin was shown to be equally wellabsorbed from the stomach and upper small intestine by employing the gastrointestinal tube technique (Bechgaard \& Jespersen, 1977). Both nicotinic acid and its amide are readily absorbed by diffusion. The metabolism of nicotinic acid is depicted in Figure D. Henderson and Gross (1979) reported that the absorbed nicotinic acid is actively converted to nicotinamide in the intestinal mucosa by the nicotinamide adenine dinucleotide (NAD) pathway (Enzymes a, $b, c$, and d). The first two steps involve the cytosolic phosphoribosyltransferase-catalyzed reaction (Enzyme a) of nicotinic acid to nicotinic acid mononucleotide which then reacts with ATP to form Deamido-NAD (Enzyme b). In the third step, Deamido-NAD reacts with glutamine and ATP to form NAD (Enzyme c). Finally, NAD is catbolized to nicotinamide by NAD glycohydrolase (Enzyme d). Since direct conversion of nicotinic acid to nicotinamide has not been demonstrated, the formation of nicotinamide in the body takes place only through NAD. Nicotinamide formed in the tissues is transported to the gastrointestinal tract where it can be recycled back to nicotinic acid by Enzyme e (Ijichi et al., 1966). Eurthermore, nicotinamide in the tissues can be directly incorporated into NAD by nicotinamide phosphoribosyltransferase (Enzyme f). In 


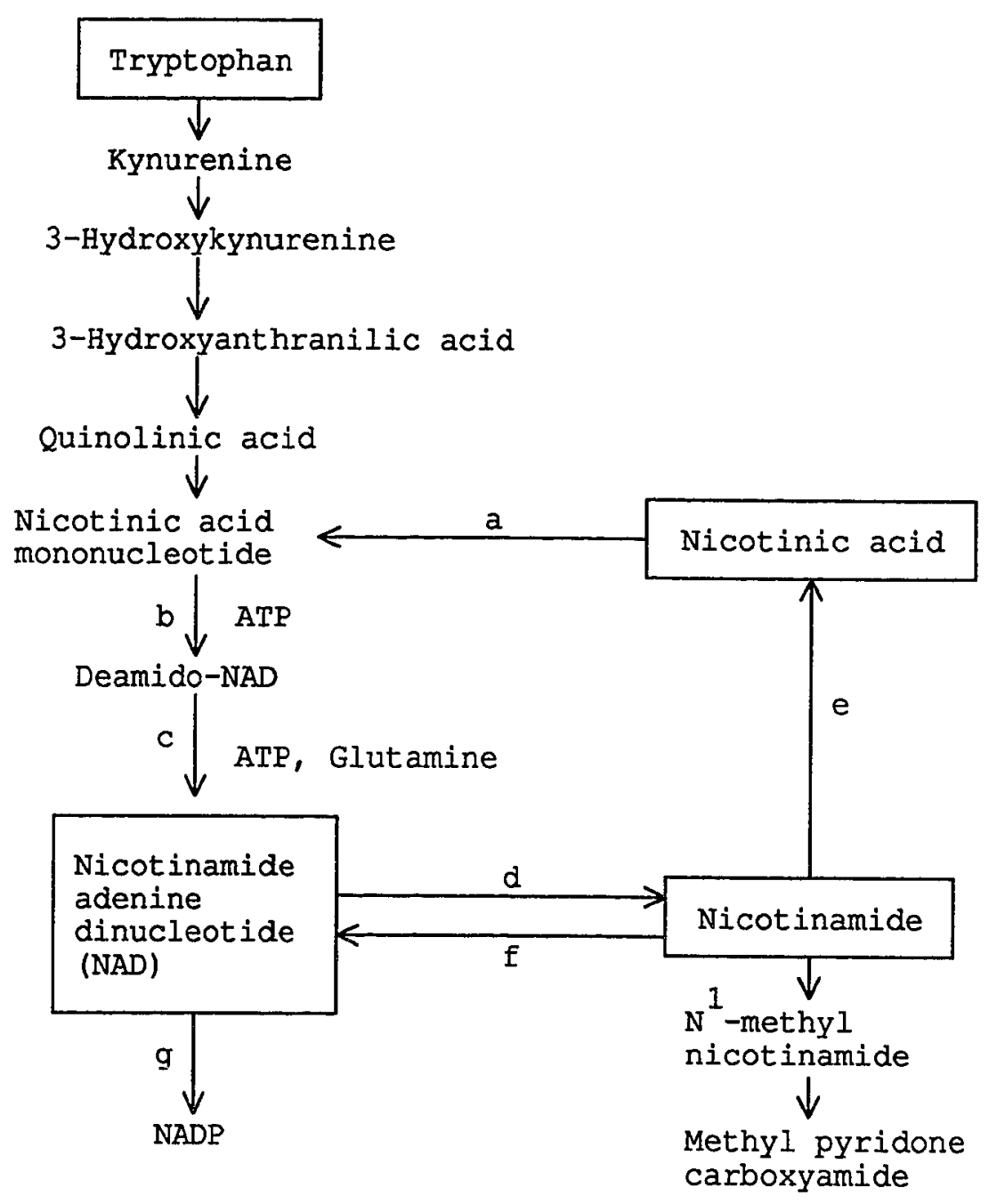

Enzymes:

a: Nicotinate phosphoribosyltransferase

b: Mononucleotide adenyltransferase

c: Synthetase

d: NAD glycohydrolase

e: Nicotinamide deamidase

f: Nicotinamide phosphoribosyltransferase

g: Kinase

Eigure D. The metabolism of tryptophan and nicotinamide nucleotides. 
addition, nicotinamide adenine dinucleotide phosphate (NADP) can be formed by a kinase-catalyzed phosphorylation of NAD (by Enzyme g) (McCormick, 1988).

Iryptophan-Niacin Conversion

In 1945, Krehl and co-workers showed that tryptophan could be substituted for dietary niacin to a certain degree in rats. Assessment of niacin requirements, therefore, takes the contribution of tryptophan into account. In humans, it is estimated that $60 \mathrm{mg}$ tryptophan can be converted to $1 \mathrm{mg}$ niacin (Goldsmith et al., 1961). This conversion ratio varies in different species. Baker et al. (1973) reported a conversion ratio of 45:1 (tryptophan: niacin) in chickens. A conversion ratio of 112:1 in turkeys was obtained by Ruiz and Harms (1990). Ducklings appear to be even less efficient than turkeys with a conversion ratio of 177:1 (Chen \& Austic, 1989). The pathway of tryptophan conversion to nicotinic acid mononucleotide in mamals is shown in Figure D.

The utilization of dietary tryptophan, nicotinamide and nicotinic acid as precursors of the nicotinamide nucleotides was studied by Bender et al. (1982). In their studies, rats were fed diets providing only one of these precursors at a time, in amounts adequate to meet their requirements for NAD and NADP synthesis. Enzyme kinetic studies suggested that the three major enzymes involved in the incorporation of 
preformed niacin into nucleotides in the liver (Enzymes a, e, and f) (Figure D) acted at or near their maximum rates at normal intracellular concentrations of nicotinamide and nicotinic acid. However, their results suggest that the ability to utilize dietary nicotinamide is very limited, and even when tissue levels of nucleotides are severely depleted, nicotinamide released by hydrolysis cannot be reutilized (Bender et al., 1982). McCreanor and Bender (1986) found that in rats a high dietary intake of tryptophan $(5.9 \mathrm{~g} / \mathrm{kg}$ diet) led to considerable increases in liver NAD/NADP ratio and urinary excretion of the niacin metabolites $\mathrm{N}^{1}$-methyl nicotinamide and methyl pyridone carboxyamide. In rats, administration of a single large oral dose of nicotinamide or nicotinic acid (up to $100 \mathrm{mg} / \mathrm{kg}$ body weight) resulted in only a small increase in the liver content of nicotinamide nucleotide coenzymes (both NAD and NADP). The results suggest that the utilization of dietary nicotinamide and nicotinic acid for NAD/NADP synthesis is limited. In contrast, NAD/NADP synthesis from the tryptophan metabolite quinolinic acid is relatively unlimited. Therefore, when preformed niacin is abundant in the tissues, there would be little or no utilization of niacin from the diet or arising from the catabolism of NAD and NADP.

In 1988, Bender and Olufunwa also reported that neither 
nicotinic acid nor nicotinamide was utilized to any significant extent as a precursor of NAD and NADP in rat liver, whereas de nova synthesis from tryptophan permitted replacement of these nucleotides. These results indicate that the liver functions syrthesis of niacin from tryptophan.

Nutritional Requirements of Niacin in Different species In humans, niacin deficiency affects primarily the skin, the gastrointestinal tract, and the central nervous system. Niacin deficiency in humans leads to pellagra. The typical presentation of pellagra is that of a chronic wasting disease associated with "the three D'S" deficiency syndrome: dermatitis, diarrhea, and dementia (Wilson, 1982). The Food and Nutrition Board (FNB) has established a Recommended Dietary Allowance (RDA) of $6.6 \mathrm{mg}$ niacin equivalents (N.E.) of niacin per day for adults for every 1000 Kilocalories consumed.

In animal studies, niacin was found to be essential for rabbits, pigs, ducks, minks, chickens, turkeys and other species of animals (Wooley \& Sebrell, 1945; Braude \& Kon, 1946; Hegsted, 1946; Warner et al., 1968; Powell \& Gehle, 1975; Ruiz \& Harms, 1988). The common symptoms of niacin deficiency in these animals are decreased growth and diarrhea. The requirements of niacin for different animals are summarized in Table I. 
Table I

Niacin Requirements of Different Species

\begin{tabular}{|l|l|l|}
\hline Species & $\begin{array}{l}\text { Requirement } \\
\text { (mg/kg diet) }\end{array}$ & Criteria used \\
\hline Human $^{1}$ & 26 & Optimal intake \\
\hline Turkey $^{2}$ & 44 & Optimal growth \\
Chicken $^{3}$ & 25 & Optimal growth \\
Duck $^{4}$ & 20 & Optimal gtowth \\
Mink $^{5}$ & $10-20$ & Optimal growth \\
Rabbit6 & 10 & Optimal growth \\
Pig7 & 10 & Optimal growth \\
\hline Entamoeba histolytica & 18, a & maximum growth \\
\hline Staphylococcus aureus & 0.059, a & maximum growth \\
\hline
\end{tabular}

$1_{\text {National Research Council (1989). Based on } 6.6 \mathrm{mg} / 1000 \mathrm{Kcal}}$ diet and $2000 \mathrm{Kcal} / \mathrm{day} / \mathrm{person}$.

$2_{\text {Ruiz \& Harms, } 1988 .}$

3Powell \& Gehle, 1975.

${ }^{4}$ Hegsted, 1946.

5 Warner et al., 1968.

$6_{\text {Wooley \& Sebrell, } 1945 .}$

7 Braude \& Kon, 1946.

${ }^{8}$ Weik \& Reeves, 1980.

9'Landy, 1938.

$a_{\mu \mathrm{g} / \mathrm{ml}}$ of medium. 
Niacin was also found to be essential for the axenic cultivation of Entamoeba histolytica, a parasitic protozoa (Weik \& Reeves, 1980). A culture medium made with liver extract and not supplemented with nicotinic acid failed to support continued multiplication of Entameeba histolytica, but did support serial subculture when niacin was added. The concentration of niacin required to achieve maximum growth was about $1 \mu \mathrm{g}$ per $\mathrm{ml}$ of medium.

In 1938, Landy reported that in Staphylococcus aureus, $0.05 \mu \mathrm{g}$ of nicotinamide per $\mathrm{ml}$ of medium was sufficient for prompt growth of cultures. In bacteriological studies, nicotinic acid and nicotinamide display different growthpromoting activities (Koser et al., 1941). In Diphtheria bacillus, nicotinic acid showed a distinctly greater growthpromoting effect (the activity of nicotinic acid:nicotinamide is $10: 1)$. The proteus group of bacteria can apparently make use of nicotinic acid about as effectively as nicotinamide, while the staphylococcus bacilli and Dysentery bacilli evidently experience more difficulty in the utilization of nicotinic acid $(1: 5)$. The Pasteurella group of bacteria is able to utilize nicotinamide, but not nicotinic acid. Toxicity

Pharmacologic doses of nicotinic acid (but not the amide) are used in humans to lower plasma lipid 
concentrations. Therapy is generally begun with single doses of 100 to $250 \mathrm{mg} /$ day. Frequency of dose and total daily dose are gradually increased until a first level therapeutic dose of 1.5 to $2.0 \mathrm{~g} /$ day is reached (Rader et al., 1992). The Recommended Dietary Allowances for niacin as a vitamin are 13 to $19 \mathrm{mg} /$ day for adult men and women aged 19 to $51+$ years (National Research Council, 1989). Doses of $2 \mathrm{~g} /$ day that are therapeutically useful for lowering serum cholesterol levels are approximately 100-fold higher than amounts of the vitamin required to meet normal adult nutritional needs. Flushing is the common side effect of nicotinic acid therapy (Rader et al., 1992). Liver toxicity (e.g. jaundice) is a potentially serious side effect of treatment with nicotinic acid. Rivin (1959) first reported elevated serum transaminase (glutamic oxaloacetic transaminase) levels in a patient treated with nicotinic acid. Nausea, vomiting, anorexia, and weakness have been reported with continued therapy with nicotinic acid (Patterson et al., 1983) .

In 1938, Chen et al. reported that with lethal or nearlethal doses of nicotinic acid, mice $(4.5 \mathrm{~g} / \mathrm{kg})$, rats $(3.5$ $\mathrm{g} / \mathrm{kg})$, and guinea pigs $(3.5 \mathrm{~g} / \mathrm{kg})$ developed convulsions, and either died promptly or recovered without apparent after effects such as irritability and weight loss. Nicotinamide caused paralysis of the respiratory center when administered 
in large doses $(1.68 \mathrm{~g} / \mathrm{kg})$. In rats nicotinamide was more toxic than nicotinic acid (Brazda \& Coulson, 1946). The presence of the carboxyl group on the $\beta$ position of pyridine decreases the toxicity of the molecule, while conversion of this group to the simple amide markedly increases toxicity. In bacterial studies, the amount of niacin was raised to $1,000 \mu \mathrm{g} / \mathrm{ml}$ before growth was distinctly retarded. In the presence of niacin at $3,000,5,000$ and $10,000 \mu \mathrm{g} / \mathrm{ml}$, growth was progressively retarded and was often completely inhibited at the $10,000 \mu \mathrm{g}$ level. At $10,000 \mu \mathrm{g} / \mathrm{ml}$ of niacin, the cells appear abnormal on microscopic examination (Koser \& Kasai, 1947). The organisms used included some which need preformed nicotinic acid and others which are able to synthesize the vitamin. They include shigella paradysenteriae, Escherichia coli, Salmonella aertrycke, Salmonella enteritidis, Proteus vulgaris, Proteus morganii, Pseudomonas fluorescens, Serratia marcescens, Agrobacterium tumefaciens, Staphylococcus aureus, Staphyloceccus albus, and Bacillus subtilis. 
CHAPTER 2

JOURNAL ARTICLE 
Authors Title Page

THE REQUIREMENT OE NIACIN AND ITS BIOSYNTHESIS FROM TRYPTOPHAN IN THE NEMATODE, Caenorhabditis elegans ${ }^{1}$

C.P. Li 2 , N.C. Lu, L.M. MCProud, and K. Sucher

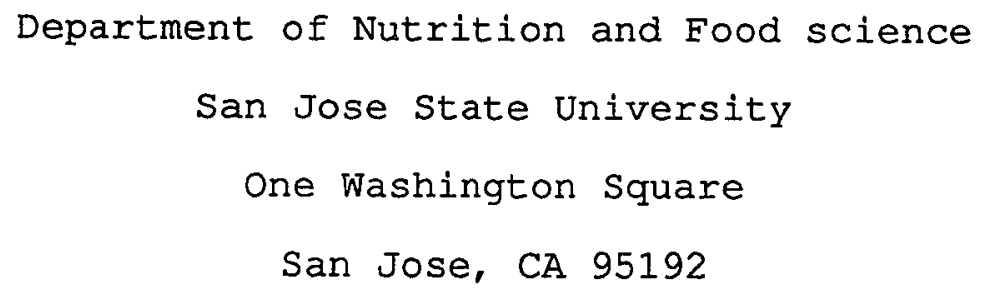

1 Supported in part by a San Jose State University Foundation Graduate Stipend Program.

2 To whom correspondence should be addressed.

Running title: Niacin Requirement of $c$. elegans 


\author{
Address all correspondence to: \\ Chih-Ping Ii \\ C/O Dr. N.C. Lu \\ Department of Nutrition and Food Science \\ San Jose State University \\ One Washington Square \\ San Jose, CA 95192 \\ (408) 924-3109
}




\begin{abstract}
The requirement for niacin was determined in the freeliving nematode, caenorhabditis elegans (c. elegans). The growth-promoting activity of 0 (control), $0.060,0.30,1.5$, $7.5,38,190$, and $940 \mu \mathrm{g} / \mathrm{ml}$ of nicotinic acid (N), nicotinamide $(\mathrm{Nm})$, and nicotinic acid plus nicotinamide $(\mathrm{N}+$ $\mathrm{Nm}$ ) was quantitatively determined. Based on the population growth of $\underline{c}$. elegans, the deficient, optimal, and toxic levels for $\mathrm{N}$ or $\mathrm{Nm}$ were below 1.5 , between 1.5 to 190 , and above $190 \mu \mathrm{g} / \mathrm{ml}$, respectively. Nicotinic acid (N) demonstrated greater growth-promoting activity than $\mathrm{Nm}$ at all levels, indicating that $\mathrm{N}$ is more active than $\mathrm{Nm}$ in the nematode. The deficient, optimal, and toxic levels for $\mathrm{N}+$ $\mathrm{Nm}$ were determined to be below 0.30 , between 0.30 to 38 , and above $38 \mu \mathrm{g} / \mathrm{ml}$, respectively. In our studies of the role of tryptophan as a niacin precursor, the basal medium contained $0.30 \mu \mathrm{g} / \mathrm{ml}$ of nicotinic acid and $180 \mu \mathrm{g} / \mathrm{ml}$ of tryptophan. The basal medium was supplemented with additional nicotinic acid $(0,0.60$, or $1.2 \mu \mathrm{g} / \mathrm{ml})$ or additional tryptophan $(0$, $180,370,550,740$, or $920 \mu \mathrm{g} / \mathrm{ml})$. Using Einney's slope ratio procedure, the conversion ratio of tryptophan to niacin was determined to be 500:1 in $c$. elegans. Compared with the conversion ratio reported in other animals, our results indicate that tryptophan is relatively ineffective
\end{abstract}


as a niacin precursor in $\mathbf{c}$. elegans.

\section{INTRODUCTION}

Caenerhabditis elegans (c. elegans) is a free-living nematode that has been cultivated under axenic (germ-free) conditions. This nematode has a short life-cycle (34 days), a rapid generation time ( 3.5 days), and the ability to be cultivated in large quantities for bioassay under defined conditions (Croll and Mathews 1977, Marx 1984). Therefore, it has become widely used as a model for nutritional research (Bolla 1987, Lu et al. 1978, Lu and Goetsch 1993, Zuckerman 1981).

The nutritional requirements of $c$. elegans for amino acids (Vanfleteren 1973), carbohydrate (Lu and Goetsch 1993), sterol (Hieb and Rothstein 1968, Lu et al. 1977), minerals (Lu et al. 1983), and heme (Hieb et al. 1970) have been investigated. The requirements for several water soluble vitamins (Augustin 1992, Lu et al. 1974, Lu et al. 1976, Sun et al. 1986) have also been determined. In 1962, Nicholas et al. reported that niacin was required by the nematode, $\boldsymbol{c}$. elegans. However, these authors did not determine the concentration of niacin necessary for optimal growth.

It is well known that the niacin requirements of many animal species can be satisfied by the administration of 
tryptophan, and that this amino acid increases intermediate metabolites for the formation of niacin. This was first established for rats by Krehl et al. in 1945. Later, it was found that niacin can be synthesized from tryptophan in other vertebrates (Baker et al. 1973, Chen and Austic 1989, Nishizuka and Hayaishi 1963, Ruiz and Harms 1990) as well as in some microorganisms (Ahmad and Moat 1966, Ortega and Brown 1960, Partridge et al. 1952, Wilson and Henderson 1963). However, the information on the conversion of tryptophan to niacin in $c$. elegans is not yet available. The objective of this study was to quantitatively determine the niacin requirement for optimal population growth in the nematode, $\mathbf{c}$. elegans. Two forms of niacin (nicotinic acid and nicotinamide) were tested to study the growth-promoting activity in $c$. elegans. In addition, the conversion ratio of tryptophan to nicotinic acid and the efficiency of tryptophan as a niacin precursor were investigated.

\section{MATERIALS AND METHODS}

Stock Media and culture. The culture conditions used were adopted from Iu and Goetsch (1993). The c. elegans stock medium was composed of $4 \frac{8}{6} \mathrm{Hi}-\mathrm{soy}, 1 \frac{8}{6}$ yeast extract, and $10 \%$ heated liver extract (HS-YE-HLE) (Tomlinson and Rothstein 1962). $\quad$ c. elegans was cultivated in 18 x $150 \mathrm{~mm}$ 
culture tubes containing $5.0 \mathrm{ml}$ of the stock medium. The cultures were incubated at $20^{\circ} \mathrm{C}$ on a tissue culture rotator at a speed of $1 \mathrm{rpm}$. The nematodes were harvested by centrifugation, washed in distilled water, and resuspended in 3.0 to $4.0 \mathrm{ml}$ distilled water contained $0.15 \mathrm{ml}$ of Caenorhabditis elegans Maintenance Medium (CeMM) (minus nicotinic acid, nicotinamide, and tryptophan) as an inoculum. The number of nematodes was determined by counting diluted cultures under a dissecting microscope. Niacin Requirement. The experimental medium used to assess niacin requirements consisted of CeMM ( $\mathrm{Lu}$ and Goetsch 1993) minus nicotinic acid, nicotinamide, and tryptophan. To determine the amounts of nicotinic acid and nicotinamide required for optimal population growth, the nematodes were grown in experimental media containing a fixed level of tryptophan $(180 \mu \mathrm{g} / \mathrm{ml})$ and varying concentrations of nicotinic acid (0 (control), $0.060,0.30,1.5,7.5,38,190$, and $940 \mu \mathrm{g} / \mathrm{ml}$ ) or nicotinamide (0 (control), 0.060, 0.30, $1.5,7.5,38,190$, and $940 \mu \mathrm{g} / \mathrm{ml})$. In a second experiment, the nematodes were grown in media containing a fixed level of tryptopohan $(180 \mu \mathrm{g} / \mathrm{mI})$ and equal concentrations of nicotinic acid and nicotinamide $(0$ (control), $0.060,0.30$, $1.5,7.5,38,190$, and $940 \mu \mathrm{g} / \mathrm{ml}$ each).

c. elegans was grown as described above. Each tube contained $5.0 \mathrm{ml}$ of experimental medium, and each culture 
was prepared in quadruplicate. The initial population was the same in each culture (600 nematodes/ml). Population growth was determined weekly, and the final population was counted on day 16.

Truptophan Requirement. Assessing niacin requirements is complicated by the conversion of dietary tryptophan to niacin in vivo (Krehl et al. 1945, Nishizuka and Hayaishi 1963). In addition, tryptophan is an essential amino acid for $c$. elegans (Vanfleteren 1973). Before determining the conversion ratio of tryptophan to niacin, we determined the level of tryptophan required to support optimal growth of $\underline{c}$. elegans at an optimal level of niacin. The culture conditions and experimental media were as described above except that varying levels of tryptophan (0 (control), 1.5, $7.4,37,180,370,740$, and $1500 \mu \mathrm{g} / \mathrm{ml}$ ) and fixed levels of nicotinic acid $(7.5 \mu \mathrm{g} / \mathrm{ml})$ and nicotinamide $(7.5 \mu \mathrm{g} / \mathrm{ml})$ were used.

Determination of Tryptophan-Niacin Conversion Ratio. To determine the tryptophan-niacin conversion ratio, nematodes were grown in a basal medium containing tryptophan (180 $\mu \mathrm{g} / \mathrm{ml})$ and nicotinic acid $(0.30 \mu \mathrm{g} / \mathrm{ml})$ but no nicotinamide. Two population growth curves were obtained. For the first growth curve, the media contained varying levels of nicotinic acid $(0.30,0.90$, or $1.5 \mu \mathrm{g} / \mathrm{ml}$ ) and a fixed level of tryptophan $(180 \mu \mathrm{g} / \mathrm{ml})$. For the second 
population growth curve, the media contained a fixed level of nicotinic acid $(0.30 \mu \mathrm{g} / \mathrm{ml})$ and varying concentrations of tryptophan $(180,360,550,730,920$, or $1100 \mu \mathrm{g} / \mathrm{ml})$. The initial inoculated population was 580 nematodes $/ \mathrm{ml}$. The slope ratio procedure (Finney 1978) was used to determine nicotinic acid-tryptophan relationships by establishing two population growth curves supported by increments of either nicotinic acid or tryptophan. Only the levels of nicotinic acid or tryptophan supported in the linear growth response were used for the multiple regression model. The 95\% confidence interval was determined for the conversion ratio by applying Fieller's theorem (Einney 1978).

Statistical Analysis. One-way analysis of variance (ANOVA) with a Sum of Squares Simultaneous Test Procedure (SS-STP) was utilized to determine statistical significance of population growth of $\mathrm{c}$. elegans at various levels of niacin or tryptophan.

RESULTS

Quantitative Requirement of Niacin. The effect of different levels of nicotinic acid (N), nicotinamide (Nm), and the combination of nicotinic acid and nicotinamide $(\mathrm{N}+$ $\mathrm{Nm})$ on population growth in $\mathrm{c}$. elegans is shown in Figure 1. We first determined the concentrations of nicotinic acid (N), nicotinamide (Nm), or nicotinic acid plus nicotinamide 
$(\mathrm{N}+\mathrm{Nm})$ required for optimal growth in $\mathrm{c}$. elegans. When $c$. elegans was cultivated in media containing no nicotinic acid (N) or nicotinamide $(\mathrm{N}+\mathrm{Nm})$, the population of nematodes decreased from the initial inoculum of 600 nematodes $/ \mathrm{ml}$ to 300 nematodes/ml on day 16. Adding nicotinic acid (N) and/or nicotinamide (Nm) to the media increased population growth. In media containing nicotinic acid (N) alone, growth of $c$. elegans was optimal over a broad range of concentrations $(1.5$ to $190 \mu \mathrm{g} / \mathrm{ml})$. At these levels, there were no significant differences in population growth. However, when nicotinic acid (N) levels were increased to $940 \mu \mathrm{g} / \mathrm{ml}$ or decreased to $0.30 \mu \mathrm{g} / \mathrm{ml}$, population growth dropped significantly $(p<0.05)$. In experimental media containing nicotinamide (Nm) alone, the population growth response was essentially the same as in media containing nicotinic acid (N) alone. Population growth was relatively constant at nicotinamide (Nm) levels ranging from 1.5 to 190 $\mu \mathrm{g} / \mathrm{ml}$. As nicotinamide (Nm) levels were increased to 940 $\mu \mathrm{g} / \mathrm{ml}$ or decreased to $0.30 \mu \mathrm{g} / \mathrm{ml}$, the nematode population decreased significantly. In media containing both nicotinic acid and nicotinamide $(N+N m)$, optimal population growth was supported by nicotinic acid plus nicotinamide $(\mathrm{N}+\mathrm{Nm})$ at $1.5 \mu \mathrm{g} / \mathrm{ml}$ each. However, population growth was relatively constant over a range of concentrations 10.30 to $38 \mu \mathrm{g} / \mathrm{ml})$. When nicotinic acid plus nicotinamide $(\mathrm{N}+\mathrm{Nm})$ 
concentrations were increased to 190 and $940 \mu \mathrm{g} / \mathrm{ml}$ or decreased to $0.060 \mu \mathrm{g} / \mathrm{ml}$, population growth fell significantly.

Growth-Promoting Activities of Nicotinic Acid And/Or Nicotinamide. We also compared the growth promoting effects of the different forms of niacin. Nicotinic acid (N) alone supported higher population growth than nicotinamide (Nm) alone at all concentrations tested (Figure 1). However, the nematodes grew to the highest density in medium supplemented with both nicotinic acid and nicotinamidde ( $+\mathrm{Nm}$ ) at 1.5 $\mu \mathrm{g} / \mathrm{ml}$ each. This combination of vitamins also exhibited the greatest toxic effects at 190 and $940 \mu \mathrm{g} / \mathrm{ml}$.

Quantitative Requirement of Tryptophan. The effect of different levels of tryptophan on population growth in $\underline{c}$. elegans is shown in Figure 2. Population growth was minimal at tryptophan levels below $37 \mu \mathrm{g} / \mathrm{ml}$ and optimal at tryptophan levels of 180 to $740 \mu \mathrm{g} / \mathrm{ml}$. As the tryptophan level increased to $1500 \mu \mathrm{g} / \mathrm{ml}$, population growth significantly decreased, indicating that this concentration of tryptophan is toxic. The results suggested that the optimal levels of tryptophan required for the growth of $c$. elegans range between 180 and $740 \mu \mathrm{g} / \mathrm{ml}$. Based on these data, a tryptophan level of $180 \mu \mathrm{g} / \mathrm{ml}$ was used in the experimental medium for determining the conversion ratio of tryptophan to niacin in $\mathcal{c}$. elegans. 
Conversion of Tryptophan to Niacin. c. elegans was cultivated in media containing varying levels of nicotinic acid $(0.30,0.90$, or $1.5 \mu \mathrm{g} / \mathrm{ml})$ and a fixed level of tryptophan $(180 \mu \mathrm{g} / \mathrm{ml})$ or in media containing a fixed level of nicotinic acid $(0.30 \mu \mathrm{g} / \mathrm{ml})$ and varying levels of tryptophan $(180,360,550,730,920$, or $1100 \mu \mathrm{g} / \mathrm{ml})$. Regression analysis of the two population growth response curves for $\boldsymbol{c}$. elegans at 16 days of cultivation on nicotinic acid supplement and tryptophan supplement is shown in Figure 3. Based on the two population growth curves, the amounts of tryptophan required to support the optimal population growth of the nematodes as compared to the optimal population growth supported by the amounts of nicotinic acid can be determined. By using Einney's slope ratio procedure (Finney 1978), an average conversion of 500:1 (tryptophan:niacin) was obtained in this study. The 95\% confidence interval for the slope ratio was 350 to 850 (determined by applying Fieller's theorem).

\section{DISCUSSION}

Nicholas et al. (1962) reported that the population level of nematodes was relatively reduced when niacin was omitted from basal medium supplemented with a crude tissue extract. The present study demonstrates an absolute 
requirement of niacin for population growth in $\mathcal{C}$. elegans. When niacin was omitted from CeMM, the nematode population decreased from the initial inoculation of 600 to 300 nematodes/ml (Figure 1). At niacin (nicotinic aicd (N) or nicotinamide (Nm)) levels of $0.060 \mu \mathrm{g} / \mathrm{ml}$, population growth increased slightly. However, the nematodes appeared much smaller, curled, and lethargic, indicating that growth and reproduction were hindered as a result of niacin deficiency. As levels of nicotinic acid (N) or nicotinamide (Nm) increased to $0.30 \mu \mathrm{g} / \mathrm{ml}$, population growth increased significantly. However, maximum population growth was not reached until the levels of nicotinic acid (N) or nicotinamide $(\mathrm{Nm})$ increased to $1.5 \mu \mathrm{g} / \mathrm{ml}$. At $940 \mu \mathrm{g} / \mathrm{ml}$, the population of $\boldsymbol{c}$. elegans significantly decreased. Therefore, optimal population growth was achieved at nicotinic acid (N) or nicotinamide (Nm) levels between 1.5 to $190 \mu \mathrm{g} / \mathrm{ml}$. Deficient and toxic levels of nicotinic acid (N) or nicotinamide (Nm) were determined to be below 1.5 $\mu \mathrm{g} / \mathrm{ml}$ and above $190 \mu \mathrm{g} / \mathrm{ml}$, respectively. Population growth supported by media containing both nicotinic acid and nicotinamide $(\mathrm{N}+\mathrm{Nm})$ was slightly greater than growth supported by nicotinic acid (N) or nicotinamide (Nm) alone. Nicotinic acid plus nicotinamide $(\mathrm{N}+\mathrm{Nm})$ concentrations between 0.30 to $38 \mu \mathrm{g} / \mathrm{ml}$ each promoted optimal growth of $\mathrm{c}$. elegans. Deficient levels of nicotinic acid plus 
nicotinamide $(\mathrm{N}+\mathrm{Nm})$ were below $0.30 \mu \mathrm{g} / \mathrm{ml}$ and toxic levels were above $38 \mu \mathrm{g} / \mathrm{ml}$. These results suggested that $\mathcal{C}$. elegans requires a minimum amount of $1.5 \mu \mathrm{g} / \mathrm{ml}$ of nicotinic acid (N) or nicotinamide (Nm) alone or a minimum of 0.30 $\mu \mathrm{g} / \mathrm{ml}$ of both nicotinic acid and nicotinamide $(\mathrm{N}+\mathrm{Nm})$ in the culture media for optimal population growth. Compared to nicotinamide (Nm), nicotinic acid (N) supported greater population growth at either deficient or optimal levels, and also had less toxic effect on $c$. elegans. Our results indicated that nicotinic acid (N) generated approximately 1.5 times greater growth-promoting activity than nicotinamide (Nm) in $\underline{c}$. elegans at all levels. In bacterial species, nicotinic acid and nicotinamide also display different growth-promoting activities (Koser et al. 1941). In Diphtheria bacillus, nicotinic acid showed a distinctly greater growth-promoting effect (nicotinic acid:nicotinamide is 10:1). The proteus group of bacteria can apparently make use of nicotinic acid about as effectively as nicotinamide, while the staphylococcus bacilli and Dysentery bacilli evidently experience more difficulty in the utilization of nicotinic acid (1:5). The Pasteurella group of bacteria is able to utilize nicotinamide only, and not nicotinic acid. In $c$. elegans, nicotinic acid plus nicotinamide $(\mathrm{N}+\mathrm{Nm})$ supported additional population growth at deficient and optimal levels 
due to the levels of nicotinic acid plus nicotinamide $(\mathrm{N}+$ $\mathrm{Nm}$ ) combined being two times greater than the levels of nicotinic acid (N) or nicotinamide (Nm) alone. Nevertheless, our results showed that the population growth supported by nicotinic acid plus nicotinamide $(\mathrm{N}+\mathrm{Nm})$ at $1.5 \mu \mathrm{g} / \mathrm{ml}$ each supported greater population growth than media containing nicotinic acid (N) or nicotinamide (Nm) alone, indicating both forms of niacin are required by $\boldsymbol{c}$. elegans for optimal population growth.

The metabolic conversion of tryptophan to niacin has been studied extensively in many animals. A ratio of 60:1 (tryptophan:niacin) is accepted for humans (Goldsmith et al. 1961). Baker et al. (1973) determined a conversion ratio of 45:1 in the chicken (Gallus domesticus). A conversion ratio of 112:1 was obtained by Ruiz and Harms in turkeys (1990). Ducklings appear to be even less efficient than turkey poults with a ratio of about 180:1 (Chen and Austic 1989). In this study, we determined that the conversion of tryptophan to niacin was 500:1 in $\varepsilon$. elegans. Thus the conversion of tryptophan to niacin in $c$. elegans appears to be much less efficient than in other animals reported. The growth response of $\mathrm{c}$. elegans to tryptophan (180 to 550 $\mu \mathrm{g} / \mathrm{ml}$ ) was weak when compared with nicotinic acid at levels of 0.30 to $1.5 \mu \mathrm{g} / \mathrm{ml}$ as described in this study (Figure 3). The domestic cat appears incapable of synthesizing 
niacin from tryptophan (da Silva et al. 1952), a phenomenon which makes it similar to the fly, Drosophila (Suchultz and Rudkin 1948), and other insects (Fraenkel and Stern 1951). The nicotinic acid requirements of two insect species, Tribolium confusum and Tenebrio molitor, have been studied in relation to the tryptophan content of their diets. It was found that dietary tryptophan could not compensate for the lack of nicotinic acid.

A tryptophan-niacin pathway (Eigure 4) has been described in mammalian liver (Nishizuka and Hayaishi 1963), Neurespera (Partridge et al. 1952) and aerobically grown yeast (Ahmad and Moat 1966). Most bacteria (Ortega and Brown 1960) do not appear to utilize tryptophan for niacin biosynthesis, except for Xanthomonas pruni (Wilson and Henderson 1963). Yanofs'ky (1954) reported that a series of nicotinic acid auxotrophs of Escherichia coli and Bacillus subtilis could utilize neither tryptophan nor any of the intermediates in the tryptophan pathway as a replacement for nicotinic acid as a growth factor. Also, these bacteria appeared to lack the enzyme, kynureninase, which splits 3hydroxykynurenine to 3-hydroxyanthranilic acid (see Figure 4) and which is essential for the conversion of tryptophan to nicotinic acid.

Nutrient metabolism in $c$. elegans is similar to that in humans and rats. In 1974, Lu et al. found that accumulation 
of formimino-L-glutamic acid (EIGLU) in nematode tissues is related to folic acid deficiency. A low lactate to pyruvate ratio is an indicator of thiamin deficiency in $c$. elegans (Augustin 1992). During the tryptophan-load test, tryptophan metabolites (xanthurenic and kynurenic acids) accumulate in the culture medium of vitamin $B_{6}$ deficient nematodes (Sun et al. 1986). However, we show in the present study that the conversion of tryptophan to niacin is very low in $\mathrm{c}$. elegans. Sun et al. (1986) reported that nematodes are able to metabolize tryptophan to 3hydroxyanthranilic acid. Our results suggest that nicotinic acid can be converted to NAD through nicotinic acid mononucleotide. Therefore, the metabolic defect in the conversion of tryptophan to NAD appears to occur between 3hydroxyanthranilic acid and nicotinic acid mononucleotide in c. elegans (Figure 4).

In summary, we demonstrate optimal growth of $\mathrm{c}$. elegans at nicotinic acid plus nicotinamide concentrations of 0.30 to $38 \mu \mathrm{g} / \mathrm{ml}$ each. However, this species is unable to convert tryptophan to niacin effectively. 


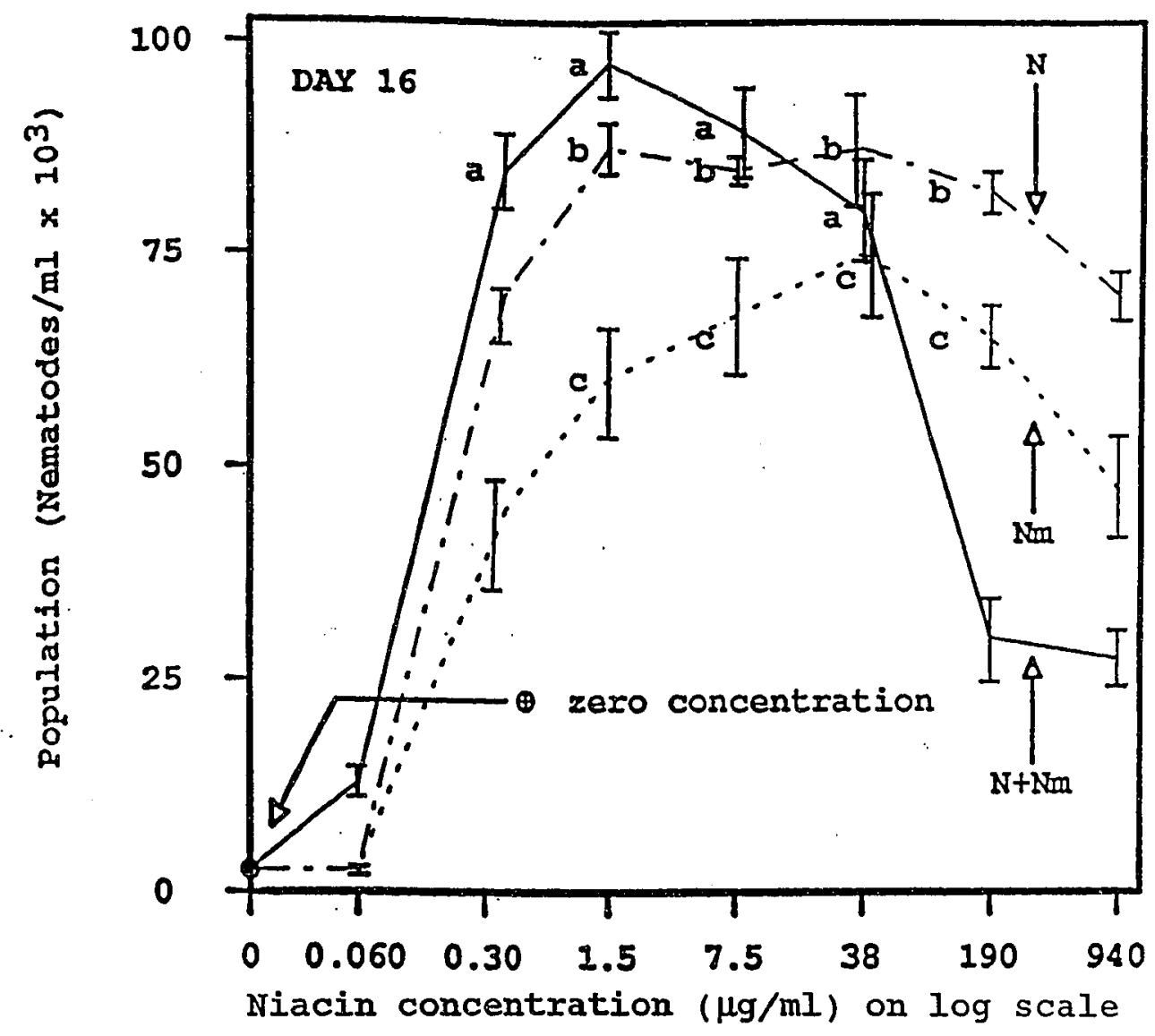

Figure 1 Effect of different levels of nicotinic acid (N), nicotinamide (Nm), and nicotinic acid plus nicotinamide $(N+$ $\mathrm{Nm}$ ) on population growth in C. elegans. Each point is the mean of quadruplicate; values respresent mean $\pm S D$. Values at each line sharing a common letter are not significantly different $(p>0: 05)$. Statistical comparisons were made with Sum of Squares Simultaneous Test Procedure (SS-STP). Tryptophan was fixed at $180 \mu \mathrm{g} / \mathrm{ml}$. Glucose $(32.5 \mathrm{mg} / \mathrm{ml})$ was added to the medium as an energy source. The concentration of $\mathrm{N}+\mathrm{Nm}$ is the sum of $\mathrm{N}$ and $\mathrm{Nm}$ for each level. 


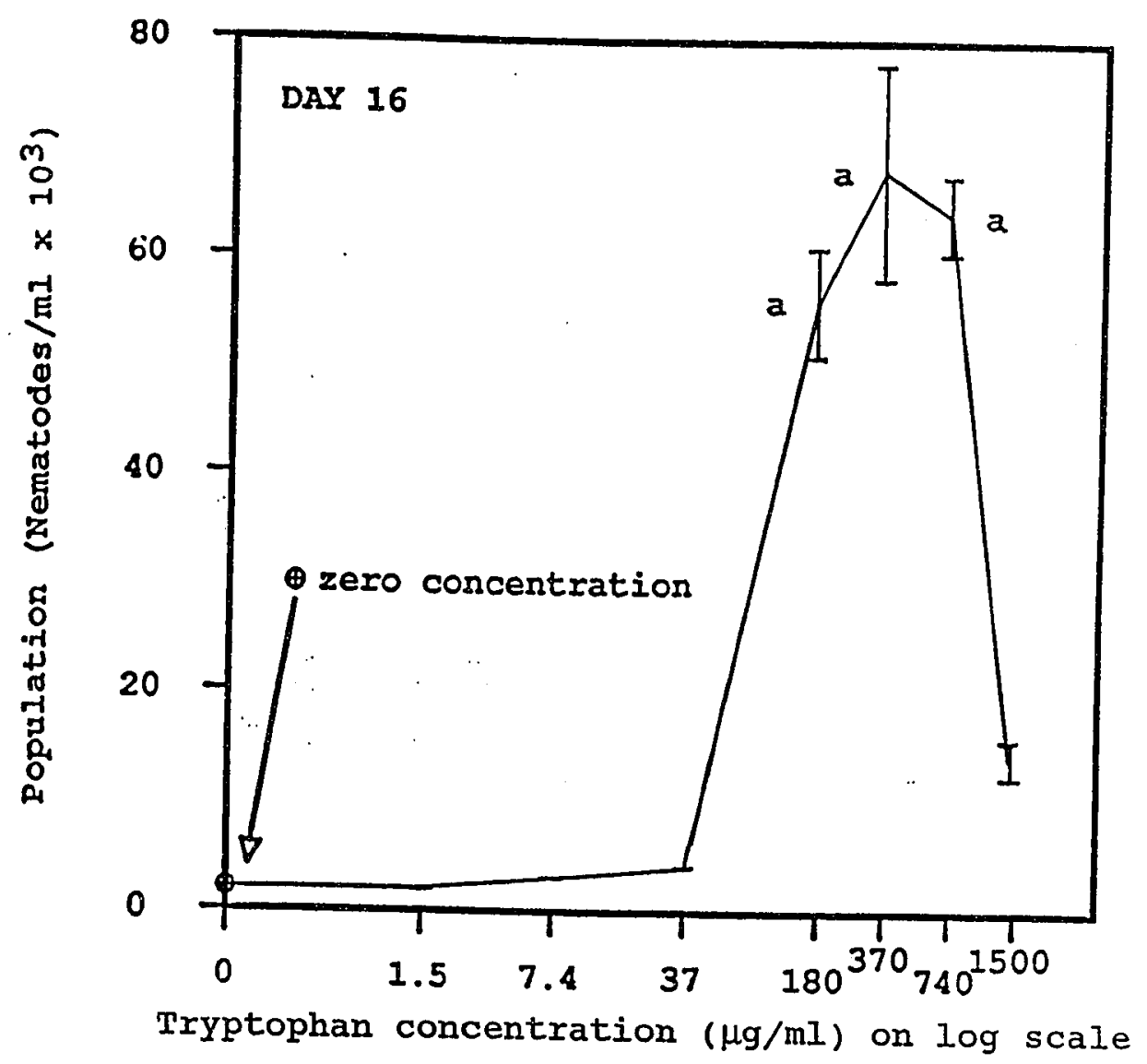

Figure 2 Effect of different levels of tryptophan on population growth in c. elegans. Each point is the mean of quadruplicate; values represent mean $\pm S D$. Values at the line sharing a common letter are not significantly different $(p>0.05)$. Statistical comparisons were made with sum of Squares Simultaneous Test Procedure (SS-STP). Concentrations of nicotinic acid $(7.5 \mu \mathrm{g} / \mathrm{ml})$ and nicotinamide $(7.5 \mu \mathrm{g} / \mathrm{ml})$ were added to the medium. Glucose $(1.3 \mathrm{mg} / \mathrm{ml})$ and potassium acetate $(5.0 \mathrm{mg} / \mathrm{ml})$ were added to the medium as energy sources. 


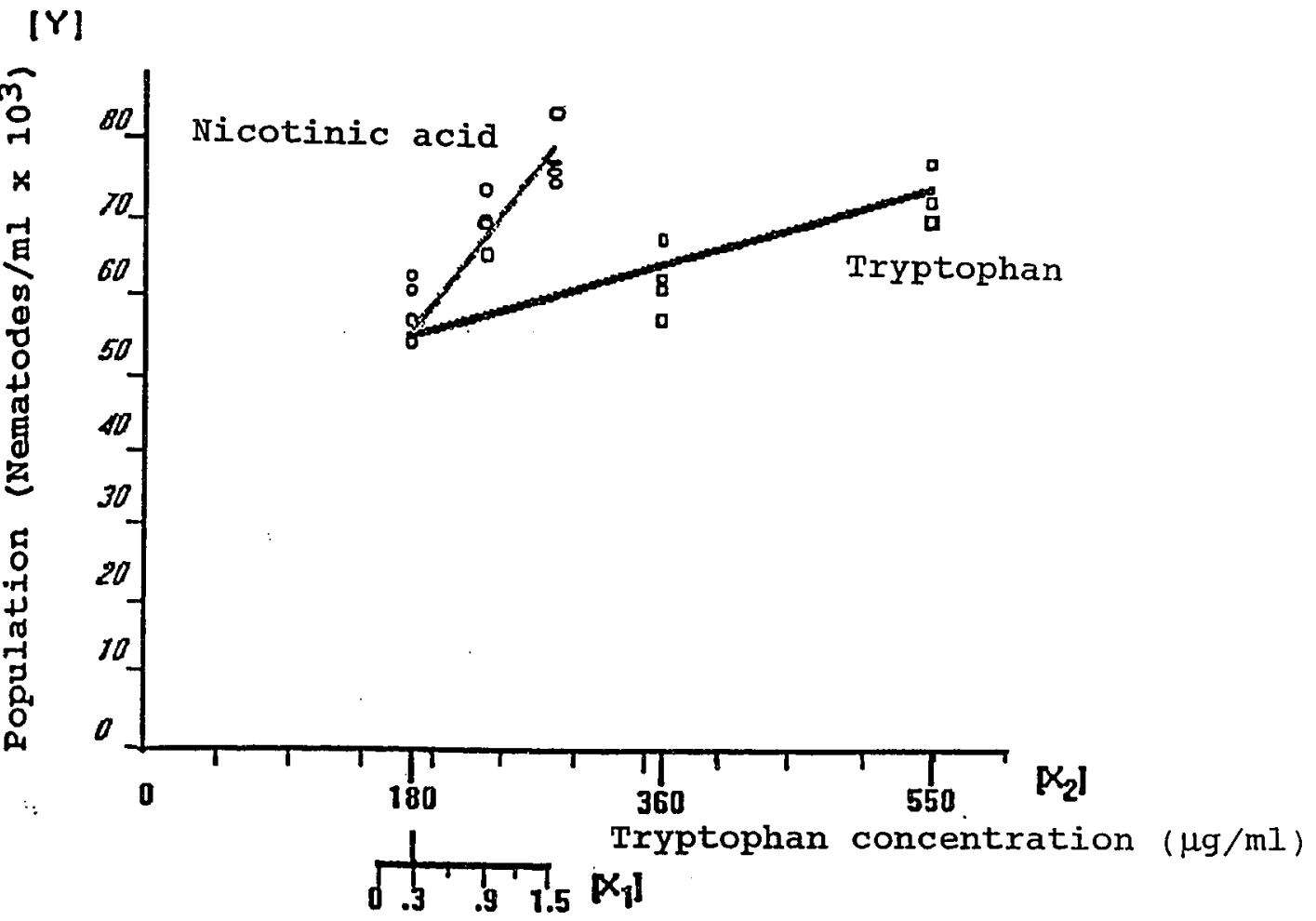

Nicotinic acid concentration $(\mu \mathrm{g} / \mathrm{ml})$

Figure 3 Regression of the population growth for $c$. elegans at 16 days of cultivation $(Y)$ on nicotinic acid supplement $\left(x_{1}\right)$ or tryptophan supplement $\left(x_{2}\right)$. The open circles represent the growth responses from the nicotinic acid supplement, and the open squares represent the growth responses from the tryptophan supplement for $\mathcal{c}$. elegans. The two lines, one light and one dark, represent the predicted equations for nicotinic acid and tryptophan respectively. $Y=\left(47.6+15.56 \mathrm{X}_{1}+0.0312 \mathrm{X}_{2}\right) \times 10^{3}$. The Initial population was 580 nematodes/ml. Glucose $(32.5$ $\mathrm{mg} / \mathrm{ml}$ ) was added to the medium as an energy source. 


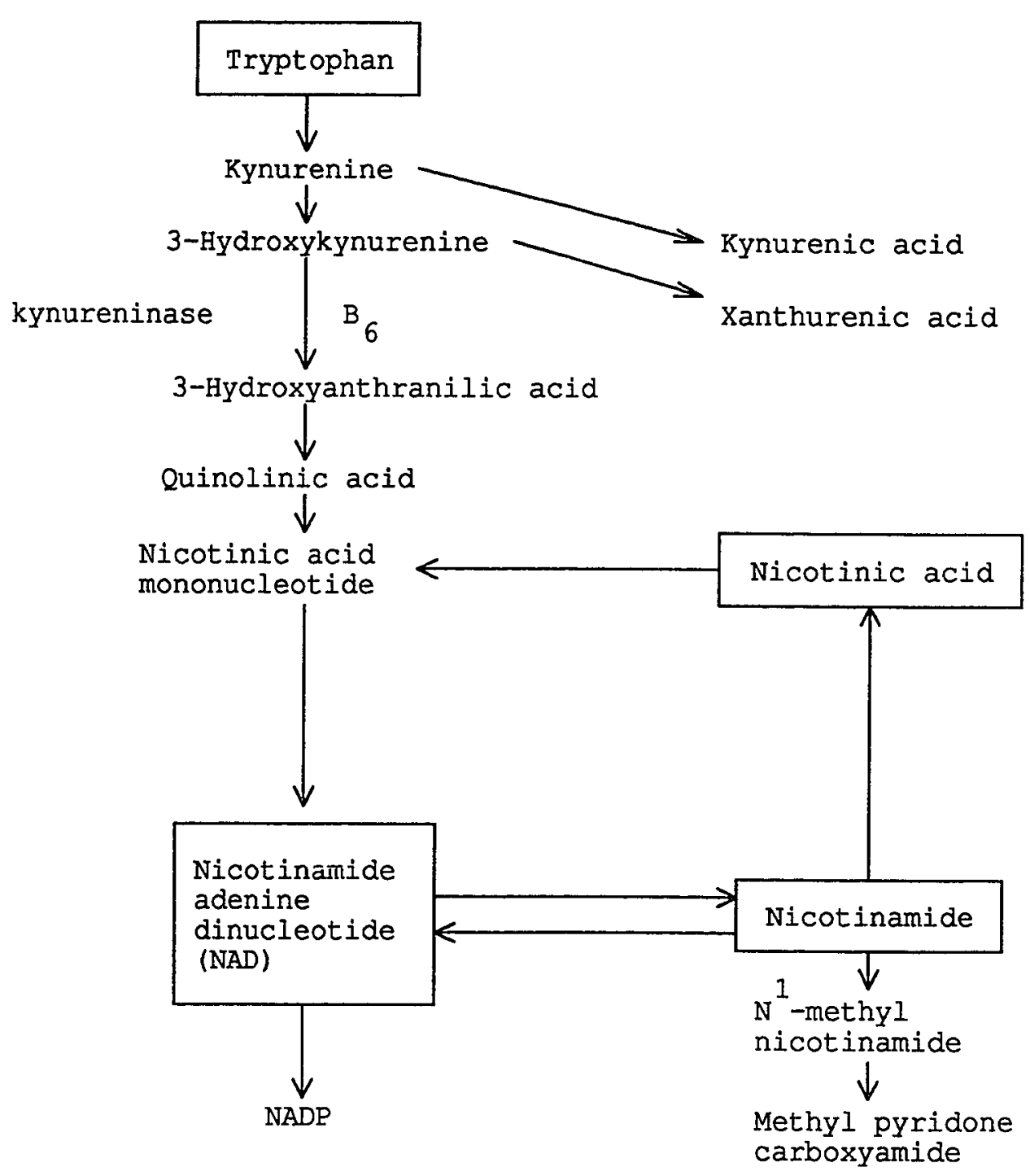

Figure 4 The metabolism of tryptophan and nicotinamide nucleotides. 


\section{References}

Ahmad, F. \& Moat, A.G. (1966) Nicotinic acid biosynthesis in prototrophs and tryptophan auxoprophs of saccharomyces cerevisiae. J Biol Chem 241: 775-780.

Augustin, J.L. (1992) Thiamin requirement and carbohydrate metabolismin the nematode, caenerhabditis

elegans. Unpublished master degree thesis, San Jose State University, San Jose, submitted to Proc Soc Exp Biol Med.

Baker, D.H., Allen, N.K. \& Kleiss, A.J. (1973) Efficiency of tryptophan as a niacin precursor in the young chick. J Anim Sci 36: 299-302.

Bolla, C. (1987) Nematodes as modelsystems for nutritional studies. In JA Veech \& DW Dickson (Eds.), Vistas on nematolegy: A commemoration of the society of nematologists (pp 424-432). Hyattsville, MD: Society of Nematologists, Inc.

Chen, B.J. \& Austic, R.E. (1989) Efficiency of tryptophanniacin conversion in chickens and ducks. Poult Sci 68 (suppl 1): 27 (Abs.) .

Croll, N.A. \& Mathews, B.E. (1977) Biology of nematode. New York: Halstead press. 
da Silva, A.C., Fried, R. \& De Angelis, R.C. (1952) The domestic cat as a laboratory animal for experimental nutrition studies. III. Niacin requirements and tryptophan metabolism. J Nutr 46: 399-402.

Einney, D.J. (1978) Statistical Method in Biological Assay. New York: Macmilllan Publishing Co.

Fraenkel, G. \& Stern, H.R. (1951) The nicotinic acid requirements of two insect species in relation to the protein content of their diets. Arch Biochem 30: 438-441. Goldsmith, G.A., Miller, O.N. \& Unglaub, W.G. (1961) Efficiency of tryptophan as a niacin precursor in man. J Nutr 73: 172-176.

Koser, S.A., Berkman, S. \& Dorfman, A. (1941) Comparative activity of nicotinic acid and nicotinamide as growth factors for microorganisms. Proc Soc Exp Biol Med 47: 504-507.

Krehl, W.A., Teply, L.J., Sarma, P.S. \& Elvehjem, C.A. (1945) Growth-retarding effect of corn in nicotinic acidlow rations and its counteraction by tryptophan. Science 101: 489-490.

Hieb, W.F. \& Rothstein, M. (1968) Sterol requirement for reproduction of a free-living nematode. Science 160: $778-780$. 
Hieb, W.F., Stokstad, E.L.R. \& Rothstein, M. (1970) Heme requirement for reproduction of the free-living nematode. Science 168:143-144.

Lu, N.C., Cheng, A.C. \& Briggs, G.M. (1983) A study of mineral requirements in $\mathbf{c}$. elegans. Nematologica 29: 425434.

Lu, N.C. \& Goetsch, K.M. (1993) Carbohydrate requirement of c. elegans and the final development of a chemically defined medium. Nematologica 39: 303-311.

Lu, N.C., Hieb, W.F. \& Stokstad, E.L.R. (1974) Accumulation of formimino-L-glutamic acid in free living nematode, $\boldsymbol{c}$. briggsae as related to folic acid deficiency. Proc Soc Exp Biol Med 145: 67-69.

Lu, N.C., Hieb, W.F. \& Stokdtad, E.L.R. (1976) Effect of B12 and folate on biosynthesis of methionine homocysteine in the nematode caenorhabditis briggsae. Proc Soc Exp Biol Med 151: 701-706.

Lu, N.C., Hugenberg, G., Briggs, G.M. \& Stokstad, E.L.R. (1978) The growth promoting activity of several lipid related compounds in the free living nematode, Caenorhabditis briggsae. Proc Soc Exp Biol Med 158: 187191.

Lu, N.C., Newton, C. \& Stokstad, E.L.R. (1977) The requirement of sterol and various sterol precursors in free-living nematodes. Nematologica 23: 57-61. 
Marx, J.L. (1984) c. elegans: Getting to know you. Science 225: $40-42$.

Nicholas, W.L., Hansen, E.L. \& Dougherty, E.C. (1962) The Bvitamin required by $\underline{c}$. briggsae (Rhabditidae). Nematologica 8: 129-135.

Nishizuka, Y. \& Hayaishi, O. (1963) Studies on the biosynthesis of nicotinamide adenine dinucleotide. I. Enzymic synthesis of niacin ribonucleotides from 3hydroxyanthranilic acid in mammalian tissues. J Biol Chem 238: $3369-3377$.

Ortega, M.V. \& Brown, G.M. (1960) Precursors of nicotinic acid in Escherichia coli. J Biol Chem 235: 2939-2945. Partridge, C.W.H., Bonner, D.M. \& Yanofsky, C. (1952) A quantitative study of the relationship between tryptophan and niacin in Neurospora. J Biol Chem 194: 269-278.

Ruiz, N. \& Harms, R.H. (1990) Conversion of tryptophan into niacin in the turkey (Meleagris gallipavos). Poult sci $69: 446-450$.

Schultz, J. \& Rudkin, Y. (1948) Absence of a sparing action of tryptophan on nicotinamide requirements of the fly Drosophila melanogaster. Fed Proc 7: 185-187.

Sun, S.J., Lu, N.C., Tseng, R. \& Smith, E. (1986) Vitamin B6 requirement and tryptophan load test in caenorhabditis. elegans. Fed Proc 45: 823. 
Tomlinson, G.A. \& Rothstein, M. (1962) Nematode biochemistry. I. Culture method. Biochim Biophys Acta $63: 465-470$.

Vanfleteren, J.R. (1973) Amino acid requirements of the free-living nematode Caenorhabditis briggsae. Nematologica 19: 93-99.

Wilson, R.G. \& Henderson, L.M. (1963) Tryptophan-niacin relationship in Xanthomonas pruni. J Bacteriol 85: 221229.

Yanofsky, C.J. (1954) Precursor of nicotinic acid in Echerichia celi and Bacillus subtilis. J Bacteriol $68: 577-571$. Zuckerman, B.M. (1981) Nematode as biology models, vol. 2. N.Y., Academy Press. 
CHAPTER 3

SUMMARY AND RECOMMENDATIONS

\begin{abstract}
Summary
The requirement of niacin (nicotinic acid, nicotinamide, and nicotinic acid plus nicotinamide) in $\mathrm{c}$. elegans was investigated. Growth-promoting activity of nicotinic acid and nicotinamide were quantitatively determined. Conversion of tryptophan into nicotinic acid was measured using Finney's slope method. The results showed that the deficient, optimal, and toxic levels for nicotinic acid or nicotinamide were below 1.5, between 1.5 to 190 , and above $190 \mu \mathrm{g} / \mathrm{ml}$, respectively. The deficient, optimal, and toxic levels of nicotinic acid plus nicotinamide were below 0.30 , between 0.30 to 38 , and above $38 \mu \mathrm{g} / \mathrm{ml}$, respectively. Nicotinic acid alone in the experimental medium showed greater growth-promoting activity than Nm alone at either deficient, optimal, or toxic levels. Using Finney's slope ratio procedure, a conversion ratio of 500:1 (tryptophan:niacin) was obtained for $c$. elegans. Our results indicate that tryptophan is less effective as a niacin precursor in $\mathcal{C}$. elegans than reported in other animal species.
\end{abstract}




\section{RECOMMENDATIONS}

To improve the experimental design of this study, the following recommendations are made.

1. In the tryptophan to niacin conversion experiment, eight culture tubes should be cultivated per level of tryptophan and niacin instead of four tubes to increase the sample size for statistical analysis.

2. The increment level of tryptophan $(180 \mu \mathrm{g} / \mathrm{ml})$ in the conversion experiment should be decreased to 50 to 100 $\mu \mathrm{g} / \mathrm{ml}$ in order to determine the peak population growth for the tryptophan supplementation.

3. To determine the major limiting step in the conversion of tryptophan to niacin in $c$. elegans, the growth-promoting effects of the intermediate metabolites (kynurenine, 3-hydroxykynurenine, 3-hydroxyanthranilic acid, and quinolinic acid) should be tested. 


\section{References}

Augustin, J.L. (1992). Thiamin requirement and carbohydrate metabolism in the nematode, caenorhabditis elegans. M.S. thesis, San Jose State University, San Jose, CA.

Baker, D.H., Allen, N.K., \& Kleiss, A.J. (1973). Efficiency of tryptophan as a niacin precursor in the young chick. Journal of Animal Science, 36, 299-302.

Bechgaard, H., \& Jespersen, S. (1977). GI absorption of niacin in humans. Journal of Pharmacetical Science, 66, $871-872$.

Bender, D.A., Magboul, B.I., \& Wynick, D. (1982). Probable mechanisms of regulation of the utilization of dietary tryptophan, nicotinamide and nicotinic acid as precursors of nicotinamide nucleotides in the rat. British Journal of Nutrition, 48, 119-127.

Bender D.A., \& Olufunwa, R. (1988). Utilization of tryptophan, nicotinamide and nicotinic acid as precursors for nicotinamide nucleotide synthesis in isolated rat Iiver cells. British Journal of Nutrition, 59, 279-287. Bolla, C. (1987). Nematodes as model systems for nutritional studies. In J.A. Veech \& D.W. Dickson (Eds.), Vistas on nematology: A commemoration of the society of nematologists (pp. 424-432). Hyattsville, MD: Society of Nematologists, Inc. 
Braude, R., \& Kon, S.K. (1946). Observations on the nicotinic acid requirements of pigs. Biechemical Journal, 44. $843-855$.

Brazda, F.G., \& Coulson, R.A. (1946). Toxicity of nicotinic acid and some of its derivatives. Proceeding of the Society for Experimental Biology and Medicine, 62, 19-20. Brun, J. (1965) . Genetic adaption of Caenorhabditis elegans (nematode) to high temperatures, Science, 150, 1467. Buecher, E.J., Hauser, E.I., \& Yarwood, E.A. (1966). Ficoll activation of a protein essential for maturation of the free-living nematodes, Caenorhabditis briggsae. Proceedings of the society for Experimental Biology and Medicine, 121, 390-393.

Chen, B.J., \& Austic, R.E. (1989). Efficiency of tryptophan-niacin conversion in chickens and ducks. Roultry Science, 68 (suppl. 1), 27. Chen, K.K., Rose, C.L., \& Robbins, E.B. (1938). Toxicity of nicotinic acid. Rroceeding of the society for Experimental Biolegy and Medicine, 38, 241-245. Croll, N.A., \& Mathews, B.E. (1977). Biology of nematodes. New York: Halstead press.

Fatt, H.V., \& Dougherty, E.C. (1963). Genetic control of differential heat tolerance in two strains of the nematode Caenorhabditis elegans. Science, 141, 266-267. 
Eriedman, P.A., Platzer, E.G., \& Eby, J.E. (1977). Species differentiation in $c$. briggsae and $c$. elegans. Journal of Nematology, 2, 197-203.

Goldsmith, G.A., Miller, O.N. \& Unglaub, W.G. (1961) . Efficiency of tryptophan as a niacin precursor in man. Journal of Nutrition, 73, 172-176.

Hansen, E.L., \& Buecher, E.J. (1970). Biochemical approach to systematic studies with axenic nematodes. Journal of Nematology, 2, 1-6.

Hegsted, D.M. (1946). Nutritional studies with the duck. Journal of Nutrition, 32, 467-472.

Henderson, L.M., \& Gross, C.J. (1979). Metabolism of niacin and nicinamide in perfused rat intestine. Journal of Nutrition, 109, 654-662.

Hieb, W.F., \& Rothstein, M. (1968). Sterol requirement for reproduction of a free-living nematode. Science, 160, $770-780$.

Hieb, W.F., Stokstad, E.L.R., \& Rothstein, M. (1970). Heme requirement for reproduction of a free living nematode. Science, 168, 143-144. 
Ijichi, H. Ichiyama, A., \& Hayaishi, O. (1966). Studies on the biosynthesis of nicotinamide adenine dinucleotide III. Comparative in vivo studies on nicotinic acid, nicotinamide and quinolinic acid as precursors of nicotinamide adenine dinucleotide. Journal of Biological Chemistry, 241, 3701-3703.

Kenyon, C. (1988). The nematode c. elegans. Science, 240, 1448-1453.

Koser, S.A., Berkman, S., \& Dorfman, A. (1941). Comparative activity of nicotinic acid and nicotinamide as growth factors for microorganisms. Rroceedings of the seciety for Experimental Biology and Medicine, 47, 504-507.

Koser, S.A., \& Kasai, G.J. (1947). The effect of large amounts of nicotinic acid and nicotinamide on bacterial growth. Journal of Bacteriology, 54, 20.

Krehl, W.A., Teply, L.J., Sarma, P.S. \& Elvehjem, C.A. (1945). Growth-retarding effect of corn in nicotinic acid-low rations and its counteraction by tryptophan. Science, 101, 489-490.

Landy, M. (1938). Effect of nicotinic acid, its isomers and related compounds upon nutrition of Staphylececcus aureus. Proceeding of the Society for Experimental Biology and Medicine, 38, 504-506. 
Lee, H.M., Ellis, R.M., \& Sigal, M.V. (1961). Some insulinlike effects observed with isolated rat epididymal adipose tissue. Biechemical Biophysical Acta, 49, 408410 .

Lu, N.C., Cheng, A.C., \& Briggs, G.M. (1983). A study of mineral requirements in $c$. elegans. Nematelogica, 29, $425-434$

Lu, N.C., \& Goetsch, K.M. (1993). Carbohydrate requirement of caenorhabditis elegans and the final development of a chemically defined medium. Nematologica, 39, 303-311.

Lu, N.C., Hieb, W.F., \& Stokstad, E.L.R. (1974). Accumulation of formimino-L-glutamic acid in free living nematode, $\underline{c}$. briggsae as related to folic acid deficiency. Proceeding of the Society for Experimental Biology and Medicine, 145, 67-69.

Lu, N.C., Hieb, W.F., \& Stokstad, E.L.R. (1976). Effect of vitamin B12 and folate on biosynthesis of methionine from homocysteine in the nematode caenorhabditis briggsae. Proceedings of the Society for Experimental Biology and Medicine, 151, 701-706.

Lu, N.C., Hugenberg, G., Briggs, G.M., \& Stokstad, E.L.R. (1978). The growth promoting activity of several lipid related compounds in the free living nematode, Caenorhabditis briggsae. Proceeding of the society for Experimental Bielogy and Medicine, 158, 187-191. 
Lu, N.C., Newton, C., \& Stokstad, E.L.R. (1977). The requirement of sterol and various sterol precursors in free-living nematodes. Nematologica, 23, 57-61. Marx, J.L. (1984). c. elegans: Getting to know you. Science, 225, 40-42.

McCormick, D.B. (1988). Niacin. In M.E. Shils \& V.R. Young (Eds.), Modern nutrition in health and disease (7th ed., pp. 370-375). Philadelphia: Lea \& Fibiger. McCreanor, G., \& Bender, D.A. (1986). The metabolism of high intakes of tryptophan, nicotinamide and nicotinic acid in the rat. British Journal of Nutrition, 56, 577586.

Mertz, W., Toepfer, E.W., \& Roginski, E.E. (1974). Present knowledge of the role of chromium. Federation Proceedings, 33, 2275-2280.

National Research Council. (1989). Recommended Dietary Allowances. 10th ed. Washington, DC: National Academy Press.

Nicholas, w.L. (1984). The biology of the free-living nematodes (2nd ed.). Oxford: Clarendon Press. Nicholas, W.L., Hansen, E.L., \& Dougherty, E.C. (1962). The B-vitamin required by $\boldsymbol{c}$. briggsae (Rhabditidae) . Nematologica, 8, 129-135. 
Nicholas, W.L., \& Jantunen, R. (1963). A biotin requirement for c. briggsae (Rhabditidae). Nematologica, 2, 332-336. Nomenclature Policy. (1979). Generic, descriptors and trival vinames for vitamins and related compounds. Journal of Nutrition, 109, 8-15.

Nomenclature Policy. (1979). Descriptors and trivial names for vitamins and related compounds. Journal of Nutrition, $109,8-15$.

Patterson D.J., Dew, E.W., Gyorkey, F., \& Graham D.Y.

(1983). Niacin hepatitis. Southern Medical Journal, 76, $239-241$.

Powell, T.S., \& Gehle, M.H. (1975). The effect of dietary tryptophan and niacin levels on broiler breeder pullets. Poultry science, 54, 1438-1442.

Rader, J.I., Calvert, R.J., \& Hathcock, J.N. (1992). Hepatic toxicity of unmodified and time-release preparations of niacin. The American Journal of Medicine, 22. $77-81$.

Riddle, D.I. (1982) . Developmental biology of $\mathcal{C}$. elegans: Symposium introduction. Jeurnal of Nematology, 14, 238239 .

Rivin A.U. (1959). Jaundice occurring during nicotinic acid therapy for hypercholesterolemia. Journal of American Medical Association, 170, 2088-2089. 
Ruiz, N., \& Harms, R.H. (1988). Niacin requirement of turkey poults fed a corn-soybean meal diet from 1 to 21 days of age. Poultry science, 67, 760-765.

Ruiz, N., \& Harms, R.H. (1990). Conversion of tryptophan into niacin in the turkey (Meleagris gallipavos). Roultry Science, 62, 446-450.

Snell, E.E. (1953). Summary of known metabolic functions of nicotinic acid, riboflavin, and vitamin $B_{6}$. Physiological Reviews, 33, 509-524.

Sun, S.J., Lu, N.C. Tseng, R., \& Smith, E. (1986). Vitamin $\mathrm{B}_{6}$ requirement and tryptophan load test in caenerhabditis elegans. Eederation Proceedings, 45, 823.

Taylor, W.M., \& Halperin, M.L. (1979). Stimulation of glucose transport in rat adipocytes by insulin, adenosine, nicotinic acid and hydrogen peroxide, role of adenosine 3':5'-cyclic monophosphate. Biechemical Journal, 178, 381-389.

Tomlinson, G.A., \& Rothstein, M. (1962). Nematode biochemistry, I. Culture method. Biochimica et Biophysica Acta, 63, 465-470.

Urberg, M., \& Zemel, M.B. (1987). Evidence for synergism between chromium and nicotinic acid in the control of glucose tolerance in elderly humans. Metabolism, 36, 896899 . 
Vanfleteren, J.R. (1973). Amino acid requirements of the free-living nematode Caenorhabditis briggsae. Nematologica, 19, 93-99.

Warner, R.G., Travis, H.F., Bassett, C.F., McCarthy, B., \& Abernathy, R.P. (1968). Niacin requirement of growing mink. Journal of Nutrition, 25, 563-568.

Weber, H.E. (1992). Effect of zinc levels on population growth and tissue $\mathrm{zinc}$ in the nematode caenerhabditis elegans. M.S. project, San Jose State University, San Jose, CA.

Weik, R.R., \& R.E. Reeves. (1980). Niacin requirement for growth of axenic Entamoeba histolytica. American Journal of Medical Hygiene, 29, 1201-1204.

Wilson, J.A. (1982). Disorders of vitamins: Deficiency, excess and errors of metabolism. In R.G. Petersdorf, R.D. Adams, E. Braunwald, K. Isselbacher, J.B. Martin, \& J.D. Wilson (Eds.), Harrison's principles of internal medicine (10th ed., pp. 461-470). New York: McGraw-Hill. Wooley, J.G., \& Sebrell, W.H. (1945). Niacin (nicotinic acid), an essential growth factor for rabbits fed a purified diet. Journal of Nutrition, 21, 191-199. Zuckerman, B.M. (1981). Nematode as biology models, vol. 2. N.Y., Academy Press. 
Appendix I

COMPONENTS OF CAENORHABITIS ELEGANS MAINTENANCE MEDIUMa

I. Vitamins \& Growth Factors

$\begin{array}{cc}\text { MWb } & . \text { gm } \\ 222.2 & 0.01500 \\ 1355.4 & 0.00375 \\ 122.1 & 0.00750 \\ 554.7 & 0.00375 \\ 238.3 & 0.00750 \\ 241.1 & 0.00375 \\ 205.6 & 0.00750 \\ 247.1 & 0.00375 \\ 514.4 & 0.00750 \\ 337.3 & 0.00750 \\ 244.3 & 0.00375 \\ 123.1 & 0.00750 \\ 441.4 & 0.00750 \\ 206.3 & 0.00375 \\ 307.3 & 0.20400 \\ 295.3 & 0.08850 \\ 180.2 & 0.06450 \\ 137.1 & 0.00750\end{array}$

II. Salts

$\mathrm{CaCl}_{2} \cdot 2 \mathrm{H}_{2} \mathrm{O}$

147.0

170.5

197.9

136.3

136.1

324.4

392.2

58.3

210.1

0.2205
0.0065
0.0222
0.0102
1.2255
0.4860
0.0588
0.1740
0.6303

III. Amino Acids

A. Essential Amind Acids

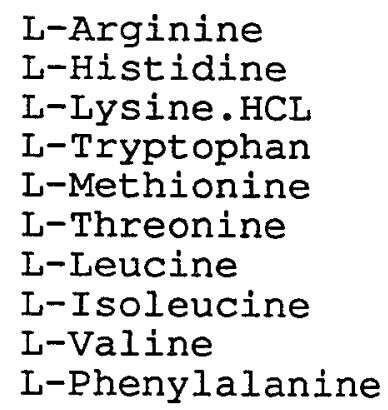

174.2

0.9750

155.2

0.2830

182.6

1.2830

204.2

0.1840

149.2

0.3890

119.1

0.7170

131.2

1.4390

131.2

0.8610

117.1

1.0200

165.2

0.6230 
Appendix I (continued)

B. Non-essential Amind Acids

\begin{tabular}{rc}
\multicolumn{1}{c}{ MWb } & $g m C$ \\
165.2 & 0.1800 \\
181.2 & 0.2720 \\
89.1 & 1.3950 \\
133.1 & 1.6200 \\
175.6 & 0.0280 \\
187.1 & 0.5500 \\
146.2 & 1.4630 \\
75.1 & 0.7220 \\
115.1 & 0.6530 \\
105.1 & 0.7880
\end{tabular}

IV. Nucleic Acid Substituents

Adenosine-3'-(2')-Phosphoric Acid. $\mathrm{H} 2 \mathrm{O}$

Cytidine-3' (2')-Phosphoric Acid

L-Phenylalanine

L-Tyrosine

L-Alanine

L-Aspartic Acid

L-Cysteine. HCL. $\mathrm{H}_{2} \mathrm{O}$

$\mathrm{L}$-Glutamate $(\mathrm{Na}) \cdot \mathrm{H}_{2} \mathrm{O}$

L-Glutamine

Glycine

L-Proline

L-Serine

105.1

0.7880

Guanosine $-3^{\prime}-\left(2^{\prime}\right)-\mathrm{PO}_{4}(\mathrm{Na})_{2} \cdot \mathrm{H}_{2} \mathrm{O}$

Uridine-3'-(2')-Phosphoric Acid

Thymine

$365.2 \quad 0.3652$

$323.2 \quad 0.3232$

$425.2 \quad 0.3632$

$324.2 \quad 0.3242$

$126.1 \quad 0.1261$

V. Other Growth Factors

Cytochrome C

$\beta$-Sitosterol

12384.0

0.0500

$414.7 \quad 0.0500$

VI. Enegry Source

D-glucose

or K-Acetated

180.2

98.1

32.5000

5.0000

VII. Solvents

$\mathrm{KOH}$

Triethanolamine (TEA)

56.1

149.2

1308.0

0.0325

Tween 80

1.2500

a Lu and Goetsch, 1993.

bolecular Weight

$\mathrm{Cgm} / 500 \mathrm{ml}$ (2X)

$\mathrm{d}_{\mathrm{A}}$ minimal $1.3 \mathrm{gm} / 500 \mathrm{ml}$ glucose is also included

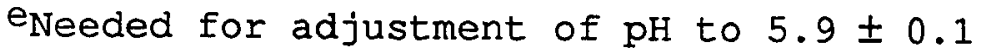

